\title{
Diverse self-association properties within a family of phage packaging RNAs
}

\author{
YUMENG HAO ${ }^{1}$ and JEFFREY S. KIEFT ${ }^{1,2}$ \\ ${ }^{1}$ Department of Biochemistry and Molecular Genetics and ${ }^{2}$ Howard Hughes Medical Institute, University of Colorado Denver, \\ School of Medicine, Aurora, Colorado 80045, USA
}

\begin{abstract}
The packaging RNA (pRNA) found in phi29 bacteriophage is an essential component of a molecular motor that packages the phage's DNA genome. The pRNA forms higher-order multimers by intermolecular "kissing" interactions between identical molecules. The phi29 pRNA is a proven building block for nanotechnology and a model to explore the rare phenomenon of naturally occurring RNA self-association. Although the self-association properties of the phi29 pRNA have been extensively studied and this pRNA is used in nanotechnology, the characteristics of phylogenetically related pRNAs with divergent sequences are comparatively underexplored. These diverse pRNAs may lend new insight into both the rules governing RNA self-association and for RNA engineering. Therefore, we used a combination of biochemical and biophysical methods to resolve ambiguities in the proposed secondary structures of pRNAs from M2, GA1, SF5, and B103 phage, and to discover that different naturally occurring pRNAs form multimers of different stoichiometry and thermostability. Indeed, the M2 pRNA formed multimers that were particularly thermostable and may be more useful than phi29 pRNA for many applications. To determine if diverse pRNA behaviors are conferred by different kissing loop sequences, we designed and tested chimeric RNAs based on our revised secondary structural models. We found that although the kissing loops are essential for self-association, the critical determinant of multimer stability and stoichiometry is likely the diverse three-way junctions found in these RNAs. Using known features of RNA three-way junctions and solved structures of phi29 pRNA's junction, we propose a model for how different junctions affect self-association.
\end{abstract}

Keywords: packaging RNA (pRNA); RNA structure; RNA self-association; DNA packaging; nanomachines

\section{INTRODUCTION}

The only naturally occurring RNA known to form a biologically functional higher-order multimer by intermolecular interaction of identical molecules is found in the phi29 family of bacteriophage. This packaging RNA ( $\mathrm{pRNA}$ ) is an essential component of the packaging motor used to drive the phage genomic DNA into the empty capsid. This motor is unique in that in addition to multiple copies of a connector protein (gp10) and an ATPase (gp16), it also contains several copies of the phage-encoded noncoding pRNA (Guo et al. 1987a,b; Meijer et al. 2001). The motor uses ATP hydrolysis to package $\sim 19.3 \mathrm{~kb}$ of dsDNA through its ring-like structure into the capsid in $<5$ min against a back pressure of $\sim 57 \mathrm{pN}$ (Fig. 1A; Guo et al. 1987a,b, 2006; Simpson et al. 2001; Smith et al. 2001; Guasch et al. 2002; Serwer 2003; Guo 2005; Fuller et al. 2007; Hugel et al. 2007; Morais et al. 2008; Rao and Feiss 2008; Aathavan et al. 2009; Lee et al. 2009; Fu et al. 2010; Ding et al. 2011). For phage phi29, the full-length transcribed pRNA is $174 \mathrm{nt}$ long, but a $120 \mathrm{nt}$-long truncated version is suf-

Corresponding author: Jeffrey.Kieft@ucdenver.edu

Article published online ahead of print. Article and publication date are at http://www.rnajournal.org/cgi/doi/10.1261/rna.045948.114. ficient for in vitro packaging (Fig. 1B; Bailey et al. 1990; Reid et al. 1994a,b; Garver and Guo 1997; Bourassa and Major 2002). The pRNA self-associates to form a ring (Simpson et al. 2001; Shu et al. 2007; Morais et al. 2008; Ding et al. 2011), which encircles the dodecameric connector protein ring using a "hand-in-hand" or "kissing loop" interaction that involves base-pairing between complementary sequences in loops of adjacent pRNA molecules (Fig. 1C; Garver and Guo 1997; Chen et al. 1999, 2000). Although there has been some disagreement over the number of copies of pRNA in the ring (5 versus 6), it is clear that self-association is critical. Mutations that eliminate this kissing interaction and thus prevent self-association dramatically reduce the function of the motor and the infectivity of the phage (Guo et al. 1998; Garver and Guo 2000).

Studies of the phi29 pRNA have been motivated by the fact that it is a good model for understanding the specific,

(C) 2014 Hao and Kieft This article is distributed exclusively by the RNA Society for the first 12 months after the full-issue publication date (see http://rnajournal.cshlp.org/site/misc/terms.xhtml). After 12 months, it is available under a Creative Commons License (Attribution-NonCommercial 4.0 International), as described at http://creativecommons.org/licenses/ by-nc/4.0/. 

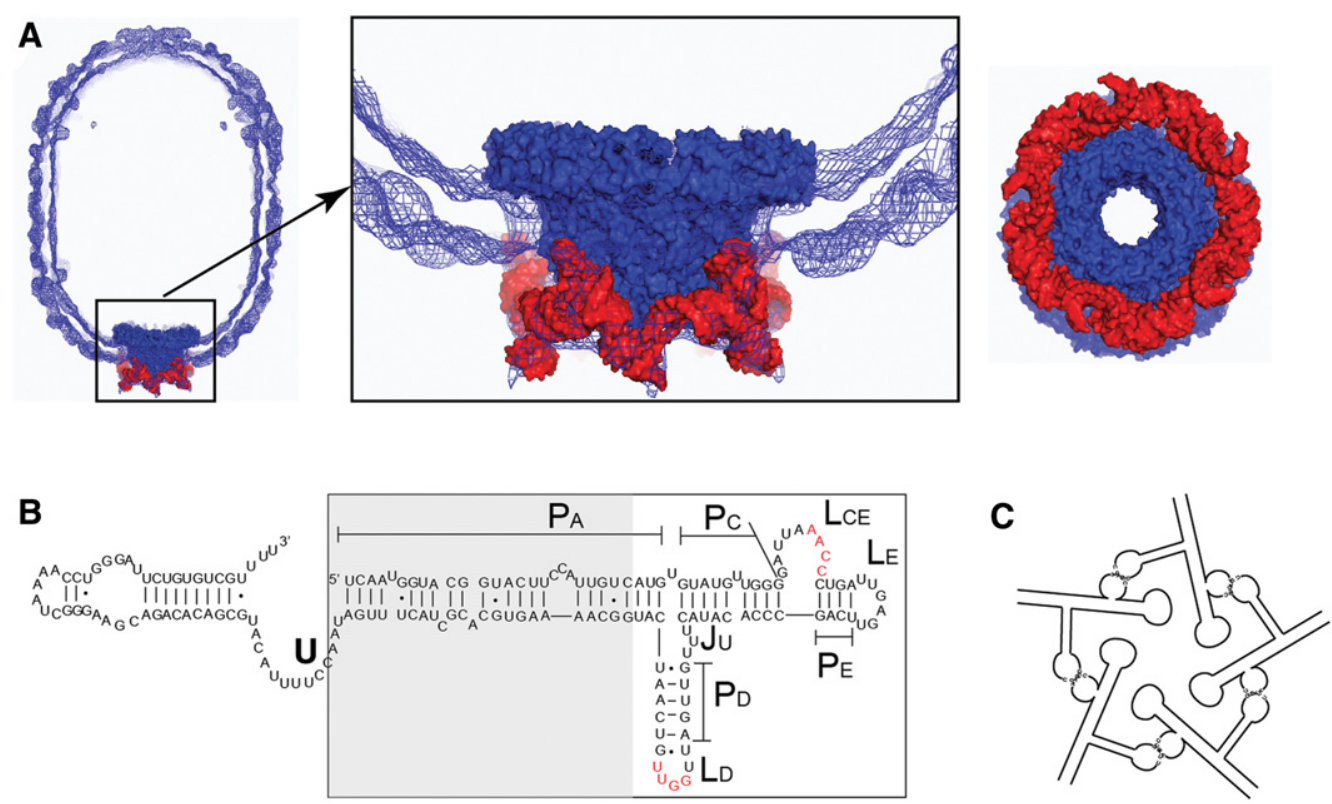

FIGURE 1. The phi29 packaging motor and phi29 packaging RNA (pRNA). (A, left) Partial model of the phi29 packaging motor based on a cryo-EM reconstruction (Morais et al. 2008), the crystal structure of phi29 packaging RNA (Ding et al. 2011), and the connector protein crystal structure (Simpson et al. 2001). The cryo-EM density and connector protein are shown in blue and pRNA in red. (Middle) Close-up view of just the motor. $\left(\right.$ Right) View of the connector protein and pRNA model only, viewed at $\sim 90^{\circ}$ angle rotation. $(B)$ Secondary structure of the phi29 pRNA. The fulllength pRNA is $174 \mathrm{nt}$, and the first $120 \mathrm{nt}$ (boxed) is necessary and sufficient for DNA packaging in vitro. The gray shaded domain is not needed for multimerization or connector interaction with the connector protein. Paired/helical (P), loop (L), and junction (J) structural elements are labeled. The kissing interaction sequences are shown in red. $(C)$ Cartoon of the "hand-in-hand" self-association of multiple pRNA copies that leads to the ring. A pentamer is shown to match the cryo-EM.

unique, and perhaps subtle properties that drive RNA selfassociation. In addition, because both naturally occurring and "designed" self-associating and self-assembling RNAs hold promise as ways to generate higher-order nanostructures (Westhof et al. 1996; Yan 2004; Ko et al. 2010; Dibrov et al. 2011; Lee et al. 2012; Ishikawa et al. 2013), the insight gained by studying pRNA can inform these efforts. Most published research on pRNA has focused on the phi29 strain, in particular the kissing hairpin interaction, the molecularity of the multimer (dimer, trimer, etc.), and how self-association contributes to phage infectivity (Chen and Guo 1997a,b; Garver and Guo 1997, 2000; Zhang et al. 1997; Guo et al. 1998; Chen et al. 1999; Trottier et al. 2000; Shu et al. 2007; Fang et al. 2008). In addition to the kissing interaction, it has been reported that the three-way junction within the phi29 pRNA has special properties including unique thermostability (Shu et al. 2011), or functionally important flexibility (Ding et al. 2011). Recent crystal structures of an engineered phi29 pRNA (Ding et al. 2011), and of an isolated phi29 pRNA three-way junction (lacking the kissing interactions) (Zhang et al. 2013) provided additional details of the intermolecular and intramolecular interactions that are important within this specific pRNA species. The knowledge resulting from these diverse studies of the phi29 pRNA has led to its adaptation as a polyvalent delivery vector and it has been useful for various types of RNA engineering (Guo et al. 2005, 2006; Li et al. 2009; Wendell et al. 2009; Shu et al. 2011;
Tarapore et al. 2011; Ye et al. 2012; Khisamutdinov et al. 2014).

The fact that basic studies of phi29 pRNA behavior has led to successful engineering suggests that even more insight into the properties that govern pRNA self-association will continue to inform engineering and therapeutic design efforts. One source of additional insight is the pRNAs found in other members of the phi29 bacteriophage family, which are surprisingly diverse in terms of their sequences (Bailey et al. 1990; Pecenkova and Paces 1999; Meijer et al. 2001). Most pRNA-centered studies have focused on the phi29 strain; in comparison the pRNAs from other strains have been relatively unexplored. Comparative studies of phylogenetically related but diverse RNAs are a powerful way to understand underlying principles of structure and function. Therefore, we took advantage of the diversity found in the pRNAs from other members of the phi29 family to examine how different pRNA sequences compared with regard to their multimerization properties. Available information predicts that within the M2, SF5, GA1, and B103 pRNAs the sequences and lengths of the putative kissing interaction sequences, and the sequences within other secondary structure features, are different (Bailey et al. 1990). We therefore initially aimed to understand if the multimers formed by these pRNAs differed in stoichiometry and thermostability, and if so, if these properties were due to different kissing interactions or other differences. During the course of our experimentation, 
another study was published in which biophysical analyses of the pRNAs from several phi29 family showed that all form multimers but with some differences in their behavior that are not just a result of the kissing loop interaction $(\mathrm{Gu}$ and Schroeder 2011). This study did not, however, examine the behavior of these pRNAs at different temperatures and also did not directly probe the location and identity of the intermolecular kissing interactions. In addition, rather than using the full $\sim 120$ nt-long pRNAs, we focused our studies on a $\sim 75$ nt-long version of the pRNA that folds independently, can interact with the packaging motor, and self-associate (Bourassa and Major 2002). We chose this strategy because this isolated multimerization domain contains both the kissing interaction and three-way junction elements proposed to be important for multimer behavior, allowing us to focus on the contributions of these elements. Also, understanding the behavior of "minimal" multimerization domains could be useful in ongoing engineering efforts and potentially structural studies.

Here, we report our findings regarding the behavior of minimal multimerizing pRNAs from the M2, GA1, SF5, and B103 strains, comparing them directly to phi29. Using chemical probing, we developed experimentally supported secondary structure models that define which bases are involved in the kissing interaction in each pRNA. Using a biochemical and biophysical approach, we (1) determined that the stability and size (number of pRNA copies) of multimers varies between these pRNAs, (2) tested the hypothesis that changes to the pRNA sequence can dramatically alter its characteristics, and (3) found that while the kissing interaction is essential, the three-way junction-containing "scaffold" within which the kissing interaction occurs may be a more important determinant of multimer size and stability. In particular, we found that the pRNA from M2 forms the most stable multimers of highest stoichiometry in solution.

\section{RESULTS}

\section{Characterization of phi29 pRNA multimerization by native gel electrophoresis}

To establish an experimental framework for examining the multimerization properties of different pRNAs, we first examined the prototype phi2 9 pRNA. By confirming that in our assays this RNA behaved as reported, we would be able to use these assays to study other pRNAs. We made four RNAs comprising nucleotides 23-97 of the phi29 pRNA as this sequence is sufficient for self-association and binding to the gp10 connector protein (Garver and Guo 1997), and also this sequence contains the kissing hairpins and threeway junction elements. The four RNAs were as follows: wild-type (WT), two mutants in which one half of the kissing interaction was mutated to abrogate this interaction (MUT1 and MUT2) and a double mutant in which the potential to form the kissing interaction was restored (COM: compen- satory mutant) (Fig. 2A). We also made a longer WT RNA (120 nt) that contained the minimal functional phi29 pRNA for direct comparison to the shorter version. We analyzed these RNAs by nondenaturing (native) polyacrylamide gel electrophoresis in both the presence of $\mathrm{MgCl}_{2}$ and in the presence of EDTA and at three different temperatures: $4^{\circ} \mathrm{C}$, $25^{\circ} \mathrm{C}$, and $37^{\circ} \mathrm{C}$. Different temperatures were used to assess the stability of the self-association interaction and its sensitivity to temperature. Native gel electrophoresis is exquisitely sensitive to differences in RNA conformations and in this case, differences in pRNA self-association.

At $4^{\circ} \mathrm{C}$, all four truncated phi2 9 pRNAs migrated as a single band on an EDTA-containing gel. Their migration rates differed slightly, probably due to expected small local differences in secondary structure (EDTA-containing gels are not fully denaturing). However, the different pRNAs showed very different behavior on an $\mathrm{Mg}^{2+}$-containing gel (Fig. 2B). WT and COM migrated more slowly than either MUT 1 or 2, consistent with the expected ability of WT and COM to self-associate and the inability of MUT1 and MUT2 to self-associate. However, WT and COM were not identical; COM migrated as a tight band while the WT band was smeared. The most straightforward interpretation is that there is exchange occurring with the WT RNA that differs in degree or rate from that with COM; this could be intramolecular conformational exchange or intermolecular association-dissociation. The 120 nt-long version of WT also smeared, suggesting this is a genuine characteristic of the pRNA. At $25^{\circ} \mathrm{C}$ and $37^{\circ} \mathrm{C}$, MUT1 and MUT2 migrated at a rate consistent with no self-association. WT and COM still migrated more slowly than either MUT1 or MUT2, but WT now migrated more quickly than COM. This is consistent with WT and COM self-association, but the two have different conformational properties and/or multimer stabilities.

To better link the observed migration patterns with self-association, we took advantage of the fact that although MUT1 and MUT2 were mutated to block self-association, they should be able to interact with each other to form multimers. To test this, MUT1 and MUT2 were mixed and run on native gels (Fig. 2C). Combining MUT1 and MUT2 resulted in a new slower-migrating band that migrated at the same rate as WT RNA; we interpret this as the intermolecular MUT1-MUT2 multimer. These results are consistent with the conclusion that the slowly migrating WT RNA band (and by extension, $\mathrm{COM}$ ) is due to self-association of multiple identical molecules. Furthermore, although the native gel data cannot unambiguously establish the number of pRNA copies that self-associate, the fact that with equal amount of MUT1 and MUT2 only the multimer band was visible showing a 1:1 stoichiometry (Fig. 2C, lower gel) is suggestive of a dimer. The fact that WT ran similarly to the putative MUT1-MUT2 dimer suggests it (and COM) also formed dimers under these conditions. Although dimers are not the ultimate form of these RNAs within the packaging motor, they have been shown to be an authentic intermediate in the assembly of 
Downloaded from rnajournal.cshlp.org on April 26, 2023 - Published by Cold Spring Harbor Laboratory Press

A
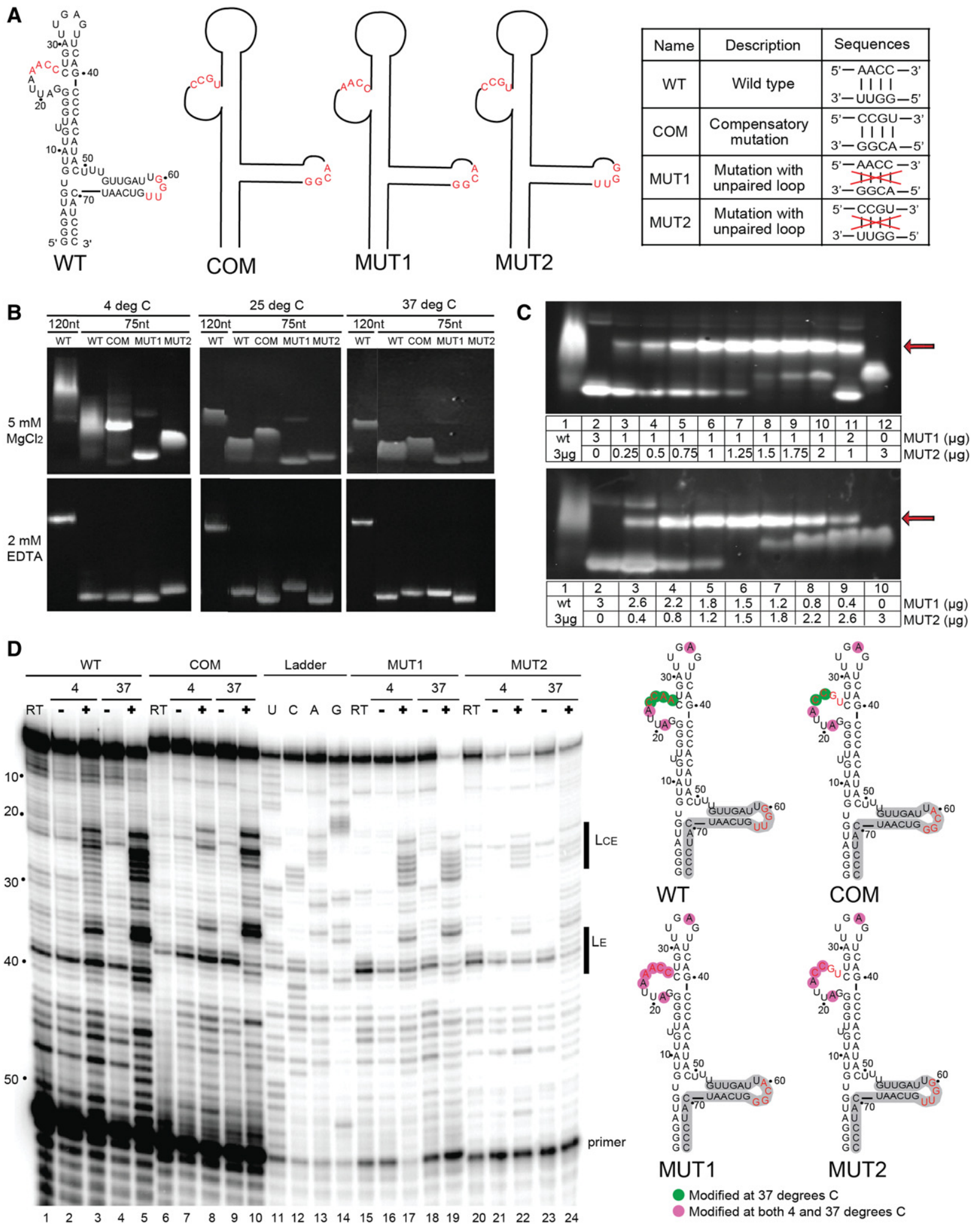

Modified at 37 degrees $C$

Modified at both 4 and 37 degrees $C$

FIGURE 2. Multimerization characterizations of phi29 constructs. (A, left) Secondary structures of the phi29 WT pRNA 75 nt-long constructs; the kissing sequences are shown in red. Cartoons of the secondary structure with mutated sequences visible in red are shown. (Right) Summary of mutations. (B) Native gel electrophoresis of different phi 29 pRNA constructs at $4^{\circ} \mathrm{C}, 25^{\circ} \mathrm{C}$, and $37^{\circ} \mathrm{C}$. Gels containing $5 \mathrm{mM} \mathrm{MgCl}_{2}$ are shown in the upper row, gels with $2 \mathrm{mM}$ EDTA are shown in the lower row. $(C)$ Native gel electrophoresis of the MUT1 and MUT2 titration experiment at $4^{\circ} \mathrm{C}$. Two sets of experiments are shown, either adding increasing amounts of MUT2 into MUT1 (upper gel) or altering MUT1 and MUT2 ratios while keeping the total RNA amounts the same (lower gel). Both experiments show a new band consistent with intermolecular interactions, highlighted by a red arrow. $(D)$ Dimethyl sulfate (DMS) probing gels of phi29 pRNAs. (RT) reverse transcription control; (-) controls without added DMS; (+) reactions with DMS; " 4 " or " 37 " indicates temperature $\left({ }^{\circ} \mathrm{C}\right)$. A sequencing ladder is included and labeled. The locations of the CE and E loops are highlighted with bars and labels to the right, nucleotide locations are indicated to the left, and the location of the primer band is shown. To the right, the analyzed data are mapped onto the secondary structures. Nucleotides modified at both $4^{\circ} \mathrm{C}$ and $37^{\circ} \mathrm{C}$ are indicated with magenta while those only modified at $37^{\circ} \mathrm{C}$ are shown in green. The nucleotides involved in forming the kissing hairpin are colored red. The primer binding location is shaded gray; these nucleotides were not visible on the gel. 
TABLE 1. Analytical ultracentrifugation measurements

\begin{tabular}{|c|c|c|c|c|c|}
\hline \multirow{2}{*}{$\frac{\text { Name }}{\text { phi29WT }}$} & \multirow{2}{*}{$\begin{array}{l}\text { Parameter } \\
\mathrm{c}(\mathrm{AU})\end{array}$} & \multicolumn{2}{|c|}{$12^{\circ} \mathrm{C}$} & \multicolumn{2}{|c|}{$25^{\circ} \mathrm{C}$} \\
\hline & & $28 \%$ & $72 \%$ & & \\
\hline & $S_{20, w}(S)$ & 3.69 & 5.51 & & \\
\hline & $D_{20, \mathrm{w}}\left(\times 10^{7} \mathrm{~cm}^{2} / \mathrm{sec}\right)$ & 7.78 & 3.98 & & \\
\hline \multirow[t]{3}{*}{ COM } & $\mathrm{C}(\mathrm{AU})$ & $7 \%$ & $93 \%$ & & \\
\hline & $S_{20, w}(S)$ & 3.00 & 4.95 & & \\
\hline & $D_{20, \mathrm{w}}\left(\times 10^{7} \mathrm{~cm}^{2} / \mathrm{sec}\right)$ & 5.88 & 5.55 & & \\
\hline \multirow[t]{3}{*}{ MUT1 } & $\mathrm{c}(\mathrm{AU})$ & \multicolumn{2}{|c|}{$100 \%$} & \multicolumn{2}{|c|}{$100 \%$} \\
\hline & $S_{20 w}(\mathrm{~S})$ & \multicolumn{2}{|c|}{2.80} & \multicolumn{2}{|c|}{3.30} \\
\hline & $D_{20, \mathrm{w}}\left(\times 10^{7} \mathrm{~cm}^{2} / \mathrm{sec}\right)$ & \multicolumn{2}{|c|}{6.22} & \multicolumn{2}{|c|}{6.33} \\
\hline \multirow[t]{3}{*}{ MUT2 } & $\mathrm{c}(\mathrm{AU})$ & \multicolumn{2}{|c|}{$100 \%$} & \multicolumn{2}{|c|}{$100 \%$} \\
\hline & $S_{20, w}(S)$ & \multicolumn{2}{|c|}{3.16} & \multicolumn{2}{|c|}{4.61} \\
\hline & $D_{20, \mathrm{w}}\left(\times 10^{7} \mathrm{~cm}^{2} / \mathrm{sec}\right)$ & \multicolumn{2}{|c|}{7.31} & \multicolumn{2}{|c|}{11.1} \\
\hline \multirow[t]{3}{*}{ M2 } & $\mathrm{C}(\mathrm{AU})$ & $77 \%$ & $23 \%$ & $30 \%$ & $70 \%$ \\
\hline & $S_{20, w}(S)$ & 5.35 & 4.64 & 5.01 & 8.09 \\
\hline & $D_{20, \mathrm{w}}\left(\times 10^{7} \mathrm{~cm}^{2} / \mathrm{sec}\right)$ & 37.2 & 1.16 & 16.49 & 9.32 \\
\hline \multirow[t]{3}{*}{ SF5 } & $\mathrm{C}(\mathrm{AU})$ & $18 \%$ & $82 \%$ & \multicolumn{2}{|c|}{$100 \%$} \\
\hline & $S_{20, w}(S)$ & 3.35 & 5.64 & \multicolumn{2}{|c|}{5.13} \\
\hline & $D_{20, \mathrm{w}}\left(\times 10^{7} \mathrm{~cm}^{2} / \mathrm{sec}\right)$ & 9.34 & 4.1 & \multicolumn{2}{|c|}{18.7} \\
\hline \multirow[t]{3}{*}{ GA1 } & $\mathrm{c}(\mathrm{AU})$ & \multicolumn{2}{|c|}{$100 \%$} & \multicolumn{2}{|c|}{$100 \%$} \\
\hline & $S_{20, w}(S)$ & \multicolumn{2}{|c|}{3.27} & \multicolumn{2}{|c|}{4.53} \\
\hline & $D_{20, \mathrm{w}}\left(\times 10^{7} \mathrm{~cm}^{2} / \mathrm{sec}\right)$ & \multicolumn{2}{|c|}{9.61} & & \\
\hline \multirow[t]{3}{*}{ B103 } & $c(A \cup)$ & $46 \%$ & $54 \%$ & $27 \%$ & $73 \%$ \\
\hline & $S_{20, w}(S)$ & 4.52 & 4.90 & 5.02 & 8.23 \\
\hline & $D_{20, \mathrm{w}}\left(\times 10^{7} \mathrm{~cm}^{2} / \mathrm{sec}\right)$ & 20.9 & 1.36 & 13.6 & 7.77 \\
\hline SF5_phi29 & $\mathrm{c}(\mathrm{AU})$ & & & $12.6 \%$ & $87.4 \%$ \\
\hline & $S_{20, w}(S)$ & & & 4.39 & 6.69 \\
\hline & $D_{20, \mathrm{w}}\left(\times 10^{7} \mathrm{~cm}^{2} / \mathrm{sec}\right)$ & & & 14.3 & 7.77 \\
\hline SF5_M2 & $\mathrm{c}(\mathrm{AU})$ & & & & \\
\hline & $S_{20, w}(S)$ & & & & \\
\hline & $D_{20, \mathrm{w}}\left(\times 10^{7} \mathrm{~cm}^{2} / \mathrm{sec}\right)$ & & & & \\
\hline
\end{tabular}

our interpretation of the native gels (Fig. 2B). Notably, the data are best fit with parameters in which COM has a higher percentage of dimer than does WT (93\% to $72 \%$, respectively), correlating with its migration on the native gel. When SVAUC was conducted at $25^{\circ} \mathrm{C}$, all phi29 pRNAs were best fit with a single-species model and the measured parameters were consistent with a monomer. We noted that at $25^{\circ} \mathrm{C}$, WT and COM showed dimer-like migration patterns on a native gel; this suggests there are subtle differences in what each technique detects, and motivated us to develop an additional experiment for querying pRNA selfassociation.

\section{Detecting self-association by chemical probing}

Since the kissing hairpin is critical in self-association, we developed a method to directly monitor this interaction that could be applied to different pRNAs. Dimethyl sulfate (DMS) probing detects base-pairing as the compound methylates the N3 of cytosine and the N1 of adenine, which are protected if the bases are in Watson-Crick base pairs (Tijerina et al. 2007). In pRNA the kissing loops

higher-order multimers (Chen et al. 2000). This is consistent with the previous results, which report dimer formation by the full-length phi29 pRNA at $4^{\circ} \mathrm{C}$ and no evidence of higher-order multimers (e.g., hexamers) on a native gel ( $\mathrm{Gu}$ and Schroeder 2011). In addition, this shows the $~ 75$-nt long version of phi29 pRNA that we used behaves similar to the fulllength pRNA reported in the literature.

\section{Examination of phi29 pRNA self-association by analytical ultracentrifugation}

To augment the native gels we used sedimentation velocity analytical ultracentrifugation (SV-AUC), which has been successfully used previously to study pRNA behavior (Robinson et al. 2006; Gu and Schroeder 2011). Experiments were performed in the presence of magnesium and at two temperatures, $12^{\circ} \mathrm{C}$ and $25^{\circ} \mathrm{C}$. At $12^{\circ} \mathrm{C}$, fitting of the data suggested MUT1 and MUT2 each exist as a single species, while data from WT and COM are best fit by a multispecies model (Table 1). For COM and WT, one of the species has parameters that are similar to those of MUT1 and MUT2. This is consistent with MUT1 and MUT2 being monomers while WT and COM self-associate, forming a mixture of monomer and multimer (hereafter interpreted as dimer). This matches contain adenines and cytosines, thus DMS probing should detect self-association by a decrease in modification in the kissing nucleotides. We used the aforementioned four phi29-based pRNAs to validate this approach. We observed that the bases in the kissing hairpins of WT and COM were modified more by DMS at $37^{\circ} \mathrm{C}$ than at $4^{\circ} \mathrm{C}$, consistent with self-association through the kissing interaction at $4^{\circ} \mathrm{C}$ but destabilization of the interaction at $37^{\circ} \mathrm{C}$ (Fig. 2D, cf. lanes 3 and 5 for WT and lanes 8 and 10 for COM). In contrast, in MUT1 and MUT2 kissing loop nucleotides were modified at both $4^{\circ} \mathrm{C}$ and $37^{\circ} \mathrm{C}$, consistent with no self-association (Fig. 2D, cf. lanes 17 and 19 for MUT1 and lanes 22 and 24 for MUT2). Adenines and cytosines which were not involved in the kissing interaction were modified at similar levels regardless of temperature, showing that the primary site of intermolecular interaction is the kissing interaction that can be readily monitored using DMS probing. Overall, the native gel, AUC and DMS probing results for the phi29 test $\sim 75$ nt constructs provides a set of self-consistent results indicating multimer (in this case, likely dimer) formation, consistent with studies of larger phi29 pRNAs ( $\mathrm{Gu}$ and Schroeder 2011), showing we have an experimental framework suitable for exploring additional pRNAs in the phi29 family. 


\section{Determining the secondary structures of pRNAs from the phi29 family}

To apply the experiments described above to pRNAs from other members of the phi29 family, we required an accurate model of the secondary structures of these RNAs and identification of the nucleotides involved in the kissing interaction. Two different secondary structure models exist in the literature for pRNAs from strains M2, SF5, GA1, and B103 (Bailey et al. 1990; Chen et al. 1999; Gu and Schroeder 2011). Although preliminary enzymatic probing was performed on M2 and SF5 (Bailey et al. 1990), these data do not provide enough resolution to unambiguously determine which of these models are correct and which nucleotides form the kissing interaction. To address this issue, we performed Selective 2'-hydroxyl acylation analyzed by primer extension (SHAPE) (Wilkinson et al. 2006), probing truncated pRNAs from the M2, SF5, GA1, and B103 strains (Fig. 3). Based on these data, it was clear that the secondary structures of Chen et al. (1999) were largely correct. These models suggest different loop composition and kissing interactions than those previously used to design mutants (Gu and Schroeder 2011).
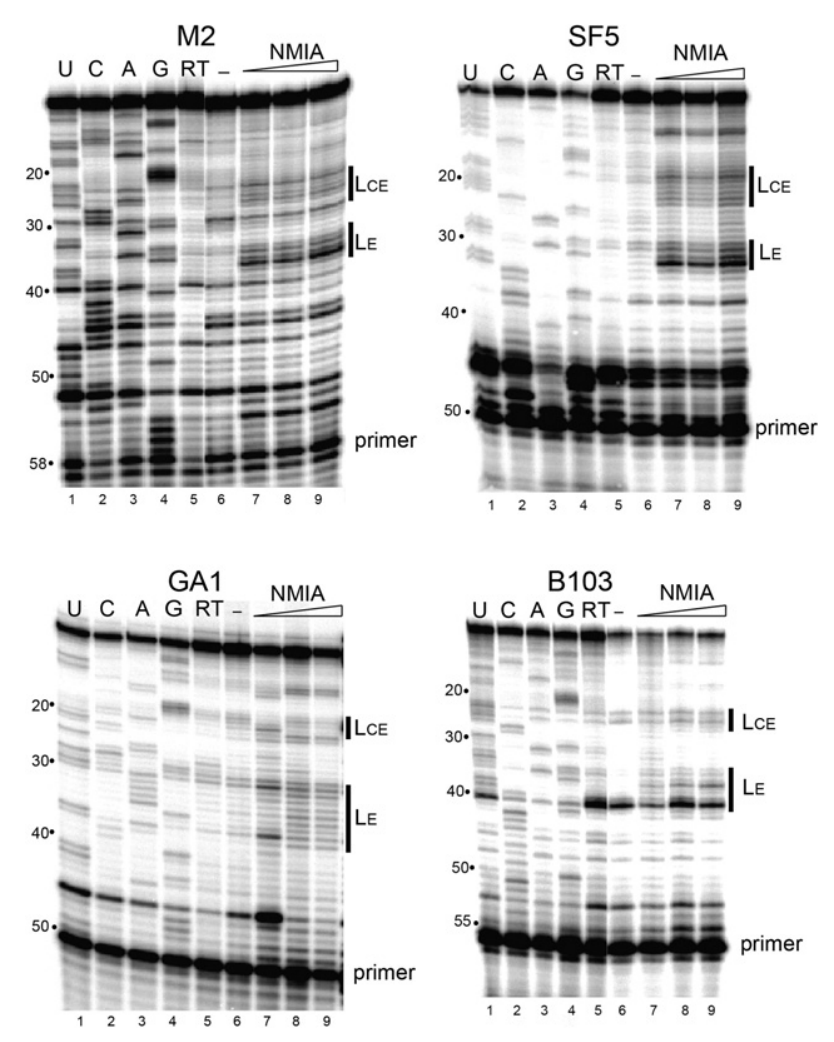

FIGURE 3. phi29 family constructs SHAPE analyses. SHAPE analysis gels of different phi29 family pRNAs are shown. (RT) reverse transcription control; (-) controls without added NMIA; reactions with increasing NMIA are indicated with white arrow. A sequencing ladder is included and labeled. The locations of the $\mathrm{CE}$ and $\mathrm{E}$ loops are highlighted with bars and labels to the right, nucleotide locations are indicated to the left, and the location of the primer band is shown.

\section{Native gels of different pRNAs reveal diverse behavior}

On native gels at $4^{\circ} \mathrm{C}$, pRNAs from M2, SF5, GA1, and B103 had similar migration rates on the EDTA-containing gel, but very different rates and behaviors on the $\mathrm{Mg}^{2+}$-containing gel (Fig. 4B). M2 and B103 pRNAs migrated primarily as a slow-moving band (relative to WT phi29 pRNA) with some smearing underneath the main band. In contrast, SF5 pRNA migrated at approximately the same rate as phi29 pRNA and was more smeared, while GA1 was a fast-migrating single band. At $25^{\circ} \mathrm{C}$ and $37^{\circ} \mathrm{C}, \mathrm{M} 2$ and $\mathrm{B} 103$ were faster and less smeared while SF5 and GA1 were single bands with similar mobility. Our preliminary interpretation is that these RNAs have different inherent propensities to self-associate and the resultant multimers have different stabilities. Specifically, M2 and B103 readily multimerize and are likely forming higher-order multimers (greater than dimer) based on their migration. This is similar to the behavior reported for larger versions of M2 pRNA (Gu and Schroeder 2011). SF5 has an intermediate ability to self-associate, and GA1 shows little self-association behavior under these conditions even at low temperature. Full-length GA1 was previously reported to have some dimerization ability and full-length SF5 was reported to associate into higher-order complexes ( $\mathrm{Gu}$ and Schroeder 2011); we did not observe these behaviors with our RNAs under these conditions. The difference in the amount of smearing of the different pRNAs suggests different degrees of conformational flexibility or rates of monomermultimer exchange.

\section{Analytical ultracentrifugation confirms a variety of self-association stabilities}

We used SV-AUC at two temperatures in a manner identical to that done for the phi29 pRNAs (Table 1). Consistent with the native gel, data for GA1 at both temperatures were best fit by a single-species model and the measured hydrodynamic properties are those of a monomer. In contrast, SF5 was best fit by a two-species model at $12^{\circ} \mathrm{C}$ but by a single-species model at $25^{\circ} \mathrm{C}$, suggesting multimers (likely dimer based on migration) are formed at lower temperature but are not stable at the higher temperature. Finally, M2 and B103 can both self-associate at both the low and high temperatures and were best fit with a model in which a significant amount of the RNA is in a multimer state (likely greater than dimer). These results correlate well with our native gel observations.

\section{Mapping the kissing interactions with chemical probing}

To verify that the sites of interaction were as predicted by our experimentally determined secondary structures, we conducted DMS probing on several different pRNA constructs under several conditions. We first probed GA1, which showed no multimerization by either SV-AUC or native gels (Fig. 4C). DMS strongly modified the run of four $A$ bases in the $\mathrm{L}_{\mathrm{E}}$ 
A

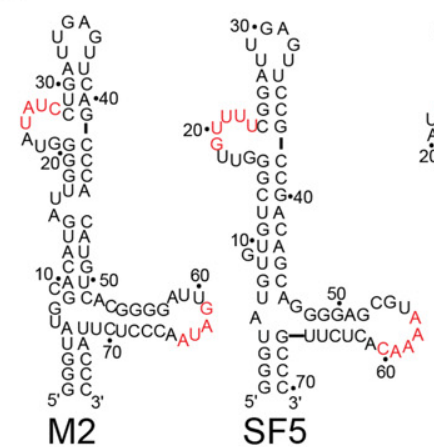

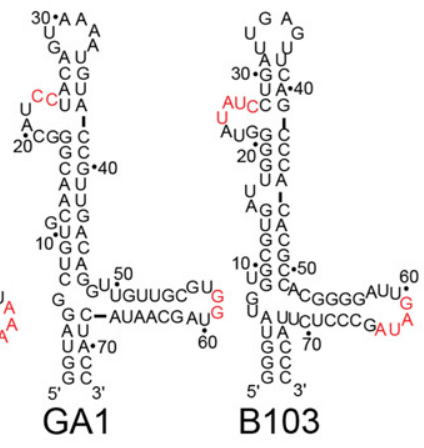

GA1

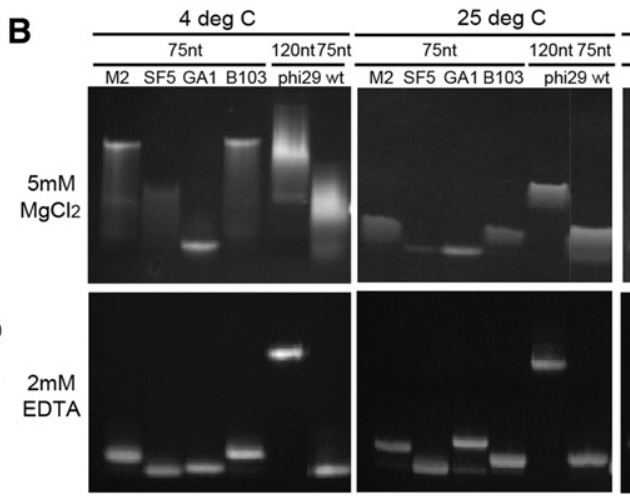

$37 \operatorname{deg} \mathrm{C}$



C

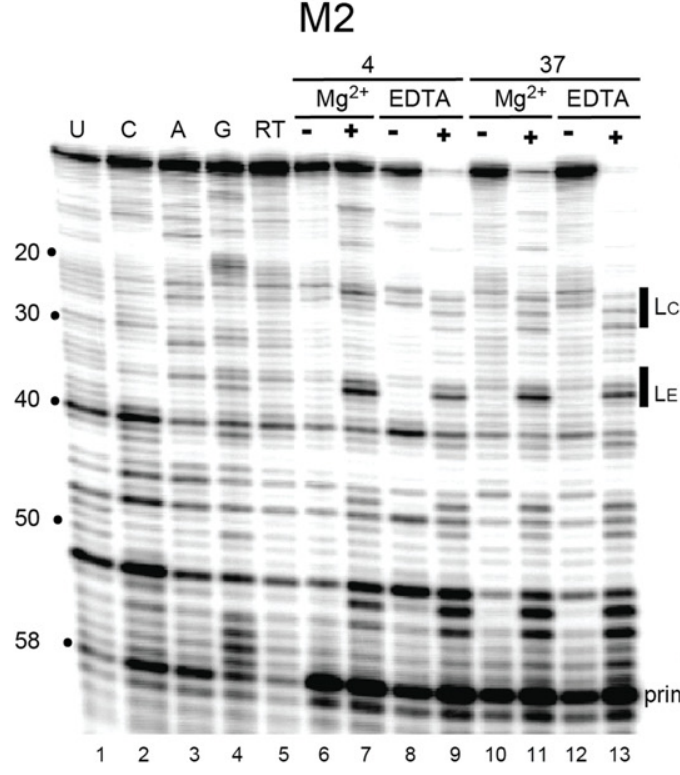

B103

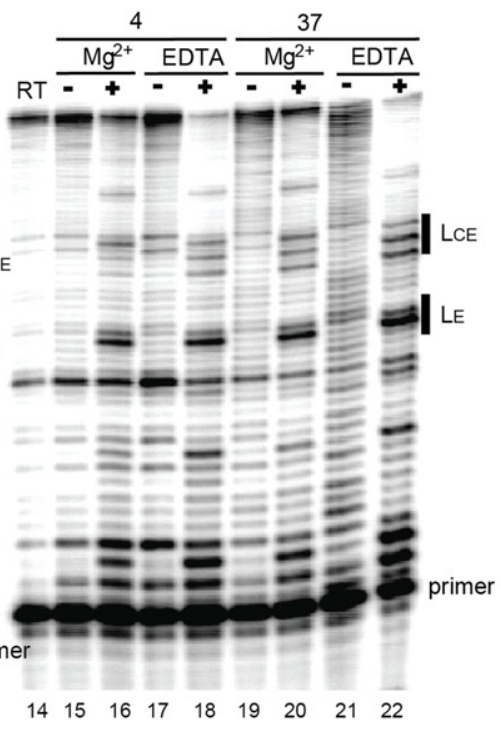

GA1



$2324252627 \quad 28293031$

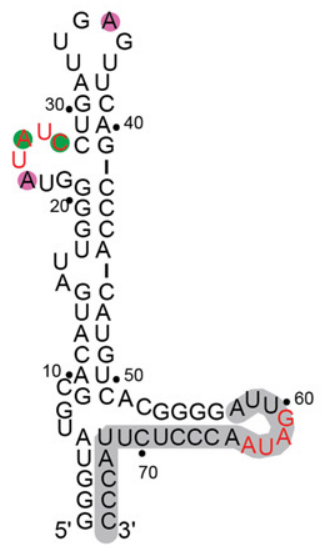

M2

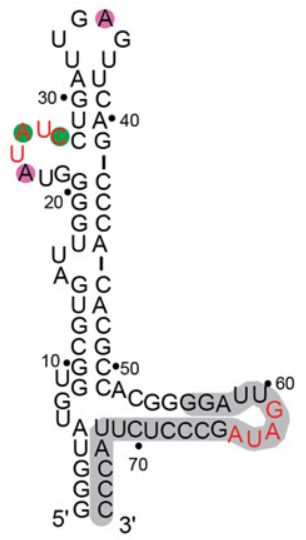

B103

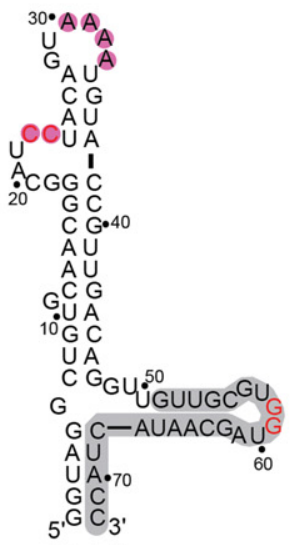

GA1

FIGURE 4. Multimerization characterization of pRNAs from the phi29 family. (A) Secondary structures of pRNAs from M2, SF5, GA1, and B103 phages. The putative kissing sequences are shown in red. (B) Native gel electrophoresis of the pRNAs in panel $A$ at different temperatures. Gels containing $5 \mathrm{mM} \mathrm{MgCl}_{2}$ are shown above while those with $2 \mathrm{mM}$ EDTA are below. (C) DMS probing of the pRNAs from panel $A$. (RT) reverse transcription control; (-) controls without added DMS; (+) reactions with DMS; "4" or " 37 " indicates temperature $\left({ }^{\circ} \mathrm{C}\right)$, and Mg ${ }^{2+}$ or EDTA indicates conditions with magnesium or EDTA. A sequencing ladder is included and labeled. The locations of the CE and E loops are highlighted with bars and labels to the right, nucleotide locations are indicated to the left, and the location of the primer band is shown. Below the gel, the analyzed data are mapped onto the secondary structures. Nucleotides modified at both $4^{\circ} \mathrm{C}$ and $37^{\circ} \mathrm{C}$ are indicated with magenta while those only modified at $37^{\circ} \mathrm{C}$ are shown in green. The nucleotides involved in forming the kissing hairpin are shown in red. The primer binding location is shaded gray; these nucleotides were not visible on the gel. 
domain at $4^{\circ} \mathrm{C}$ and $37^{\circ} \mathrm{C}$, consistent with the formation of this loop in the secondary structure and with no involvement in self-association (Fig. 4C, lanes 29 and 31). Likewise, the A and $\mathrm{C}$ bases of the $\mathrm{L}_{\mathrm{CE}}$ loop were modified similarly at both temperatures. It is worth noting that the degree of modification of the bases in $\mathrm{L}_{\mathrm{CE}}$ was not as high as those in $\mathrm{L}_{\mathrm{E}}$. This is likely due, in part, to the very strong RT stops at four heavily modified A bases that precede this loop and attenuate the RT signal. The SHAPE probing indicates conformational dynamics. Due to the location of the reverse-transcription primer on the RNA, the other half of the kissing interaction (loop $\mathrm{L}_{\mathrm{D}}$ ) was not observed. Overall, the DMS probing is consistent with the conclusion that this GAl pRNA construct does not stably self-associate to a detectable level under these conditions.

DMS probing of the M2 and B103 constructs showed behavior different than the GA1 pRNA. Specifically, like the GA1 pRNA, the $\mathrm{L}_{\mathrm{E}}$ loop was modified (in this case a single A base) to the same degree at all temperatures, consistent with no involvement in self-association. However, in the presence of $\mathrm{Mg}^{2+}$ (necessary for multimer formation), the $\mathrm{L}_{\mathrm{CE}}$ loop was modified less at $4^{\circ} \mathrm{C}$ than at $37^{\circ} \mathrm{C}$ (Fig. $4 \mathrm{C}$, cf. lanes 7 and 11 for M2, lanes 16 and 20 for B103). Notably, the nucleotides that were modified more at $37^{\circ} \mathrm{C}$ are those predicted to participate in the kissing interaction. To ensure that this change in modification was not a temperature effect, we probed these two RNAs at $4^{\circ} \mathrm{C}$ and $37^{\circ} \mathrm{C}$ in the presence of EDTA, which allowed secondary structure to form but not tertiary structure or self-association. In the presence of EDTA, the A and C bases of the loop were modified to the same degree at both temperatures, consistent with a lack of self-association (Fig. 4C, cf. lanes 9 and 13 for M2, lanes 18 and 22 for B103). Overall, the chemical probing provided information clarifying which nucleotides are involved in the kissing interaction for each pRNA and confirmed the behavior and temperature sensitivity seen in the native gels.

\section{Determining multimer size by sedimentation equilibrium analytical ultracentrifugation}

The ability to form different-sized multimers could be an important feature of diverse pRNAs and could explain the large mobility differences on the native gels (Fig. 4B). Therefore, we rigorously explored whether these 75 nt-long multimerization domains from diverse pRNAs form different-sized multimers (e.g., dimer, trimer, etc.) using sedimentation equilibrium analytical ultracentrifugation (SE-AUC). As representative RNAs, we used the M2, phi29, and MUT2 pRNAs, based on their large migration differences on native gels. To determine the suitability of this technique, we performed measurements in the presence of $\mathrm{Mg}^{2+}$, at three different pRNA concentrations, at $4^{\circ} \mathrm{C}$ and $25^{\circ} \mathrm{C}$, and at three different speeds. The resultant data were analyzed using global fitting procedures in the Heteroanalysis program to fit the curves. Examples of raw data and fit curves for the MUT2, phi29, and M2 pRNAs at a single concentration $\left(4^{\circ} \mathrm{C}\right.$ : [phi29 $\mathrm{RNA}]=0.6 \mu \mathrm{M},[\mathrm{MUT} 2 \mathrm{RNA}]=0.73 \mu \mathrm{M},[\mathrm{M} 2 \mathrm{RNA}]=$ $0.58 \mu \mathrm{M} ; 25^{\circ} \mathrm{C}$ : [phi29 RNA] $=0.86 \mu \mathrm{M}$, [MUT2 RNA] $=$ $1.0 \mu \mathrm{M},[\mathrm{M} 2 \mathrm{RNA}]=0.82 \mu \mathrm{M})$ and speed $(12 \mathrm{~K} \mathrm{rpm})$ are shown in Figure 5A. At both temperatures and for all of these RNAs, the fits are excellent.

The shapes of the SE-AUC curves indicate differences in the self-association properties of the MUT2, phi29, and M2 pRNAs at equilibrium under these conditions. Specifically, a curve that rises more steeply qualitatively indicates higher molecular weight particles and thus more self-association. Both the phi29 and M2 curves show more self-association than the MUT2 (Fig. 5B), as expected based on the native gel, SV-AUC, and chemical probing results. The differences in M2 pRNA's curve compared with phi29 pRNA's curve qualitatively suggests that in addition to forming more stable multimers, the M2 pRNA multimers are of higher order. This latter observation is consistent with the native gels in which M2 pRNA migrated more slowly than phi2 9 pRNA. At $25^{\circ}$ $\mathrm{C}$, the curves are consistent with MUT2 and phi29 pRNAs existing as monomers and M2 self-associating, again consistent with the native gel, chemical probing, and SV-AUC data.

A more quantitative analysis of the SE-AUC data was done to verify the molecularity of various pRNAs and their stabilities (Table 2). At $4^{\circ} \mathrm{C}$, the data for MUT1 pRNA was best fit by a model in which this RNA showed no self-association (100\% monomer). Likewise, when the MUT2 and GA1 pRNAs were analyzed by SE-AUC at $4^{\circ} \mathrm{C}$, they also did not show self-association, well-correlated to native gel and the SV-AUC results. The phi29 pRNA contained a mix of monomer and dimer with a higher percentage of dimer at the highest analyzed concentration (the curves reflect the populationally weighted average of monomer or multimer states). However, attempts to fit the phi29 pRNA data into models with multimers greater than dimer led to substantially poorer fits (Fig. 2). The M2 pRNA was well fit by monomer + dimer and monomer + trimer models (Table 2). These SE-AUC data alone cannot unambiguously distinguish between these models, but the native gels and its SE-AUC curve strongly suggest it can form a higher-order multimer than phi29, likely a trimer. At $25^{\circ} \mathrm{C}$ the curves of MUT2 and phi2 9 pRNAs were best fit by a monomer-only model, while M2 fit to a monomer + dimer model (GA1 and MUT1 data were not studied at $25^{\circ} \mathrm{C}$ ). The fit percentage of M2 pRNA dimer increased with higher RNA concentration, consistent with concentration-dependent self-association.

The presence of mixed populations for the phi29 and M2 pRNAs raised the question of interconversion between these species. SE-AUC can distinguish between reversible association (exchanging species) and mixture of fixed species (kinetically inert) molecules. We compared the fits of phi29 and M2 pRNAs at $4^{\circ} \mathrm{C}$ at two conditions: (1) higher pRNA concentration at lower centrifugation speed and (2) lower pRNA concentration at higher centrifugation speed. For phi29, condition (1) fit as 20\% monomer and $80 \%$ dimer and condition 
A
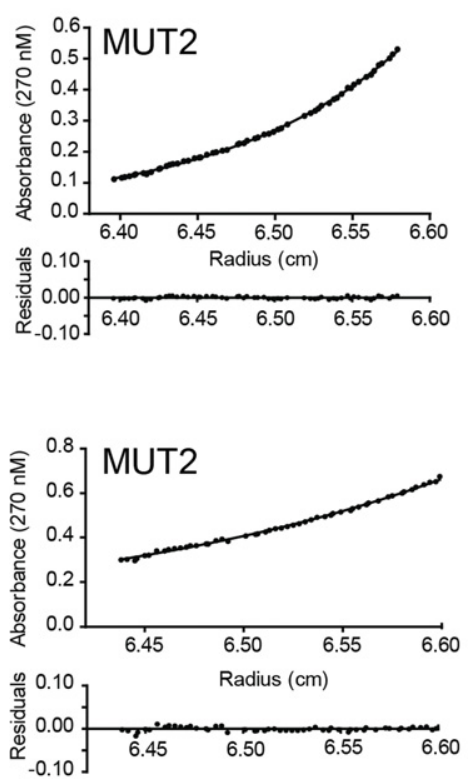

4 degrees $\mathrm{C}$

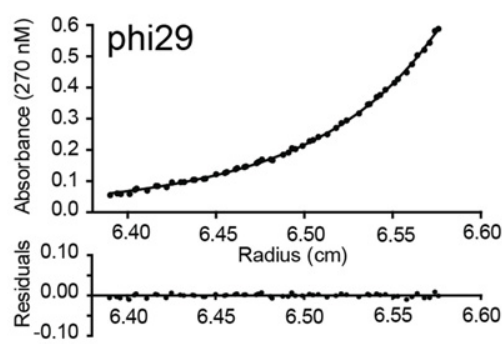

25 degrees $\mathrm{C}$
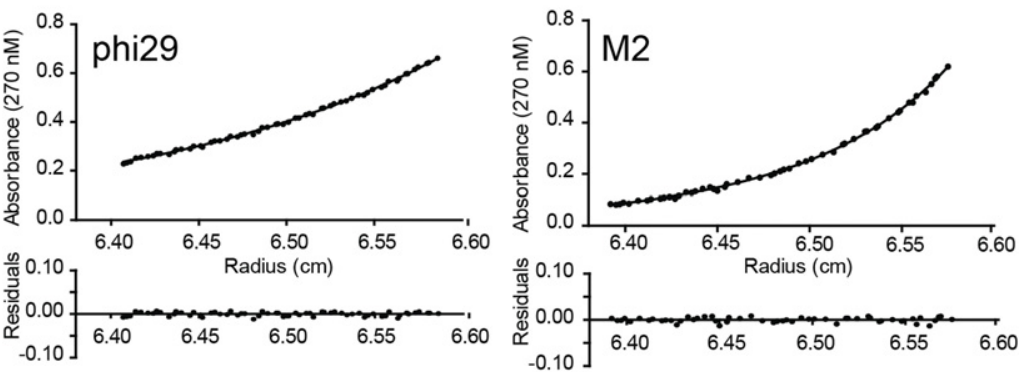
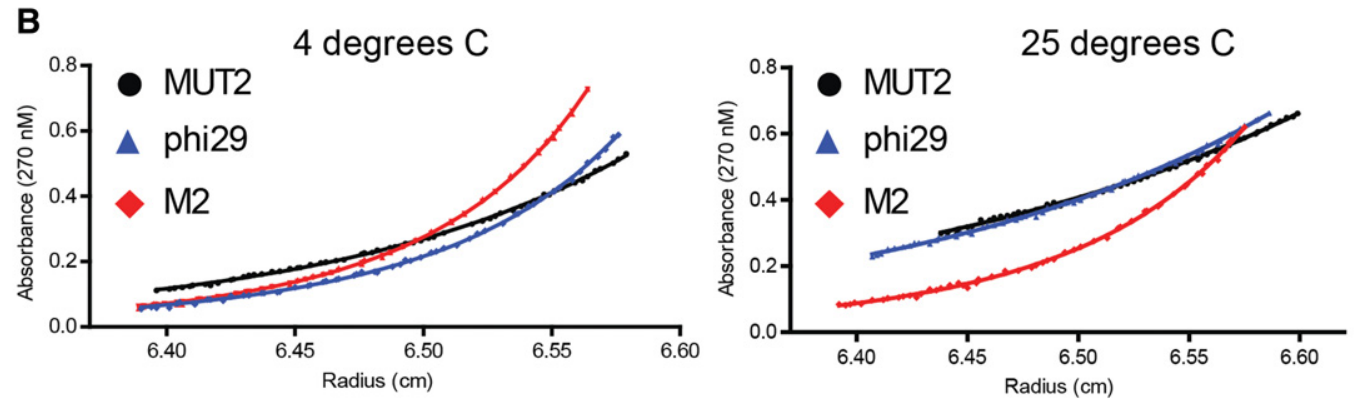

FIGURE 5. Sedimentation equilibrium analytical ultracentrifugation of three pRNAs. ( $A$, top) SE-AUC data for MUT2, phi29 and M2 pRNAs at $4^{\circ} \mathrm{C}$. Each graph contains the raw absorbance data as a function of position in the cell (black dots) with the global fit shown as a black line. The graph below contains the residuals of the fit, showing the good correlation of the fit to the raw data. (Bottom) SE-AUC data, fit, and residuals at $25^{\circ} \mathrm{C}$. $(B)$ Overlaid, fit SE-AUC data from MUT2 (black), phi29 (blue), and M2 (red) pRNAs at a single concentration and speed. (Left) $4^{\circ} \mathrm{C},($ right $) 25^{\circ} \mathrm{C}$.

TABLE 2. Sedimentation equilibrium analytical ultracentrifugation measurements

\begin{tabular}{|c|c|c|c|c|}
\hline Name & Concentration & $4^{\circ} \mathrm{C}$ & & $25^{\circ} \mathrm{C}$ \\
\hline MUT2 & $\begin{array}{l}\text { Low concentration } \\
\text { Mid concentration } \\
\text { High concentration }\end{array}$ & $100 \%$ monomer & & $100 \%$ monomer \\
\hline phi29WT & $\begin{array}{l}\text { Low concentration } \\
\text { Mid concentration } \\
\text { High concentration }\end{array}$ & $\begin{array}{l}45 \% \text { monomer, } 55 \% \text { dimer } \\
15 \% \text { monomer, } 85 \% \text { dimer } \\
20 \% \text { monomer, } 80 \% \text { dimer }\end{array}$ & $\begin{array}{l}K_{\mathrm{d}}=1.1 \times 10^{-6} \mathrm{M} \\
K_{\mathrm{d}}=2.1 \times 10^{-6} \mathrm{M} \\
K_{\mathrm{d}}=1.7 \times 10^{-6} \mathrm{M}\end{array}$ & $100 \%$ monomer \\
\hline M2 & Low concentration & $\begin{array}{l}\text { Fit } 1: 11 \% \text { monomer, } 89 \% \text { dimer } \\
\text { Fit } 2: 55 \% \text { monomer, } 45 \% \text { trimer }\end{array}$ & $K_{\mathrm{d}}=1.0 \times 10^{-6} \mathrm{M}$ & $68 \%$ monomer, $32 \%$ dimer $K_{d}=3.5 \times 10^{-6} \mathrm{M}$ \\
\hline & $\begin{array}{l}\text { Mid concentration } \\
\text { High concentration }\end{array}$ & $\begin{array}{l}\text { Fit } 1: 43 \% \text { monomer, } 57 \% \text { trimer } \\
\text { Fit 1: } 11 \% \text { monomer, } 89 \% \text { dimer } \\
\text { Fit 2: } 55 \% \text { monomer, } 45 \% \text { trimer }\end{array}$ & $\begin{array}{l}K_{\mathrm{d}}=2.9 \times 10^{-6} \mathrm{M} \\
K_{\mathrm{d}}=1.8 \times 10^{-6} \mathrm{M}\end{array}$ & $\begin{array}{l}20 \% \text { monomer, } 80 \% \text { dimer } \quad K_{\mathrm{d}}=2.7 \times 10^{-6} \mathrm{M} \\
30 \% \text { monomer, } 70 \% \text { dimer } \quad K_{\mathrm{d}}=4.1 \times 10^{-6} \mathrm{M}\end{array}$ \\
\hline MUT1 & $\begin{array}{l}\text { Low concentration } \\
\text { Mid concentration } \\
\text { High concentration }\end{array}$ & $100 \%$ monomer & & \\
\hline GA1 & $\begin{array}{l}\text { Low concentration } \\
\text { Mid concentration } \\
\text { High concentration }\end{array}$ & $100 \%$ monomer & & \\
\hline
\end{tabular}


(2) fit as $22 \%$ monomer and $78 \%$ dimer. The similarity of the monomer:multimer ratios under both conditions suggests reversible association. Assuming M2 forms trimers at $4^{\circ} \mathrm{C}$, condition (1) fit as 55\% monomer and 45\% trimer and condition (2) fit as 65\% monomer and 35\% trimer. The remarkable consistency between the SE-AUC data and the native gel analysis suggests that native gels are a reliable means to rapidly assess the self-association stoichiometry and stability of diverse $\mathrm{pRNAs.}$

\section{Initial pRNA engineering through kissing interaction exchange}

Because the kissing loop interaction is known to be essential for pRNA self-association, we explored whether the different behaviors of different $\mathrm{pRNAs}$ could be due to differences in the specific kissing loop interactions in each. We tested this by determining if the characteristics of one pRNA could be transferred to another by exchanging kissing interaction elements. Using the knowledge gleaned from our SHAPE and DMS chemical probing to choose the correct kissing sequences, the kissing loops from the stable trimeric M2 pRNA were placed into the poorly self-associating GA1 pRNA. Unfortunately, this chimeric pRNA formed an aberrant secondary structure and this precluded further analyses (for this and all other chimeric RNAs, formation of the correct secondary structure was confirmed by SHAPE probing, data not shown). Therefore, a different set of chimeric RNAs was designed using the SF5, phi29, and M2 pRNA sequences. The phi29 or M2 kissing interaction sequences were moved into the SF5 pRNA "scaffold" to make SF5_phi29 and SF5_M2 (Fig. 6A). SHAPE probing verified that these chimeric pRNAs formed the correct secondary structures (data not shown). If the kissing interaction is the primary driver of multimerization, the expectation was that on native gels SF5_phi29 would act similar to phi29 pRNA, and SF5_M2 would be like M2 pRNA.

At $4^{\circ} \mathrm{C}$, SF5_phi29 migrated at a rate consistent with dimer and similar to SF5 and phi29 WT pRNAs, while at $25^{\circ} \mathrm{C}$ it migrated more slowly, implying that it self-associates more stably than either SF5 or phi29 pRNAs. Measured by SV-AUC, at $25^{\circ} \mathrm{C}$ the SF5_phi29 chimera existed in a monomer-multimer mix (Table 1), while both SF5 and phi29 WT were only monomers. At $37^{\circ} \mathrm{C}$ SF5_phi29 migrated at a rate similar to phi29 WT and SF5, consistent with all being monomeric. In DMS probing experiments, SF5_phi29's kissing loop $\mathrm{L}_{\mathrm{CE}}$ was modified less at $4^{\circ} \mathrm{C}$ than at $37^{\circ} \mathrm{C}$, consistent with multimer formation at the lower temperature but not the higher (Fig. 6C, cf. lanes 7 and 8 to lanes 10 and 11). Thus, combining parts of SF5 with the kissing interaction of phi29 results in a chimeric "daughter" that is more stable than one of the unmodified "parents." The SF5_M2 chimera exhibited different behavior. Specifically, its migration on the native gel at $4^{\circ} \mathrm{C}$ indicated a dimer, compared with trimeric M2 pRNA (Fig. 6B). Furthermore, at $25^{\circ} \mathrm{C}$ SF5_M2 was monomeric while M2 pRNA was a dimer. SV-AUC and DMS probing indicated the self-association was unstable (Fig. 6C, cf. lanes 18 and 19 to lanes 21 and 22). Hence, M2-like behavior did not transfer with the M2 kissing interaction sequence. Analysis of these two chimeric pRNAs showed that some structural elements other than the kissing interaction are fundamental to pRNA multimer stabilization.

\section{Exploring the role of the three-way junction-containing 'scaffold'}

We hypothesized that the "scaffold" on which the kissing interaction sequences are displayed is important and defined this scaffold as the overall pRNA structure excluding the kissing hairpin, to include the $\mathrm{J}_{\mathrm{U}}$ three-way junction (3wj) present in all pRNAs but whose sequence differs dramatically between strains. To test this, chimeras containing the SF5 pRNA's kissing interaction on either the phi29 scaffold (phi29_SF5) or the M2 scaffold (M2_SF5) (Fig. 7A) were designed and tested by native gel at the stringent temperature of $25^{\circ} \mathrm{C}$. If the kissing hairpin is the only determinant of self-association behavior, then phi29_SF5 pRNAs will be similar to phi29 pRNAs, and M2_SF5's multimers will be less stable (and perhaps smaller) than M2 pRNA trimers. Conversely, if the scaffold is more important than the kissing interaction, M2_SF5's will act similarly to M2 pRNA. At $25^{\circ} \mathrm{C}$, phi29_SF5 migrates similarity to SF5 pRNA; at the higher temperature it is more SF5-like (monomeric at this temperature). In contrast, M2_SF5's major band migrates similarly to M2 pRNA. Thus, the scaffold of M2 pRNA, the pRNA that is consistently the most stable and of highest stoichiometry, was able to overcome a "mediocre" kissing interaction. These results are consistent with the assertion that the scaffold, and therefore the $3 \mathrm{wj}$, plays a crucial role in determining pRNA selfassociation characteristics, and furthermore suggests some features of the M2 pRNA scaffold are particularly favorable for forming multimers of higher stoichiometry and stability.

\section{DISCUSSION}

The pRNA is the only identified naturally occurring RNA that forms multimers via intermolecular interactions of identical molecules. Here, we studied the properties of minimal selfassociation of pRNAs from several members of the phi29 family, finding that they have diverse abilities to form multimers of different stoichiometry and thermostability; the latter characteristic has not previously been compared between different pRNAs. In all these pRNAs, the kissing interaction appears to be the point of intermolecular contact, but a key determinant of their diverse behaviors is likely the $3 w j$ which differs dramatically between pRNAs of different strains. Placed into context with published results, our data should be useful for future pRNA engineering.

Because a recent study contained experiments similar to ours ( $\mathrm{Gu}$ and Schroeder 2011), it is important to compare 

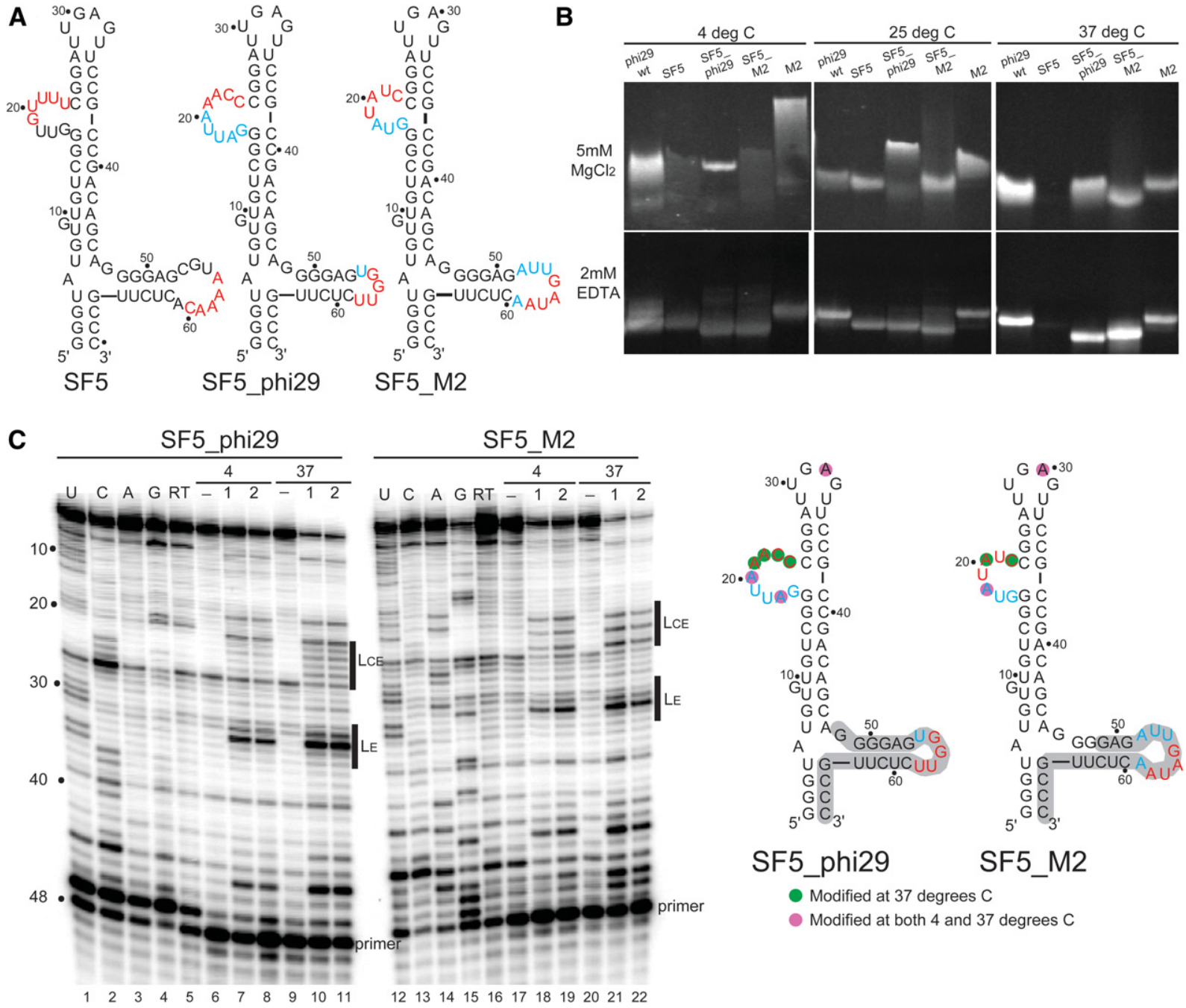



SF5 phi29

Modified at 37 degrees $C$

Modified at both 4 and 37 degrees $C$

FIGURE 6. Characterizing multimerization properties of the chimeric constructs. (A) Secondary structures of the first set of chimeric RNAs. Wildtype SF5 RNA is included for comparison. The predicted kissing sequences are in red, other nucleotides introduced by mutation are in cyan. ( $B$ ) Native gel electrophoresis of the chimeric pRNAs of panel $A$ at different temperatures. Gels containing $5 \mathrm{mM} \mathrm{MgCl}_{2}$ are shown above while those with 2 mM EDTA are below. $(C)$ DMS probing of the pRNAs from panel $A$. (RT) reverse transcription control; $(-)$ controls without added DMS; $(1,2)$ reactions with DMS; "4" or " 37 " indicates temperature $\left({ }^{\circ} \mathrm{C}\right)$. A sequencing ladder is included and labeled. The locations of the CE and E loops are highlighted with bars and labels to the right, nucleotide locations are indicated to the left, and the location of the primer band is shown. To the right, the analyzed data are mapped onto the secondary structures. Nucleotides modified at both $4^{\circ} \mathrm{C}$ and $37^{\circ} \mathrm{C}$ are indicated with magenta while those only modified at $37^{\circ} \mathrm{C}$ are shown in green. The nucleotides involved in forming the kissing hairpin are shown in red. The primer binding location is shaded gray; these nucleotides were not visible on the gel.

the results, particularly where they differ. We found that the GA1 pRNA has little or no ability to self-associate although $\mathrm{Gu}$ and Schroeder (2011) detected some dimers at $4^{\circ} \mathrm{C}$ with a longer pRNA, high $[\mathrm{RNA}]$ and $10 \mathrm{mM} \mathrm{Mg}^{2+}$. A phylogenetic study divided the phi29 phage family into three subclasses with GA1 in its own separate subclass (Bailey et al. 1990; Pecenkova and Paces 1999; Meijer et al. 2001). Perhaps GA1 pRNA may use a different mechanism to form a stable multimer, or weak multimerization of GA1 pRNA might imply that the ring requires stabilization by interaction with other motor components. Likewise, we found SF5 pRNA forms a dimer while previous data suggest SF5 forms higher-order multimers at $4^{\circ} \mathrm{C}$. Results from some of chimeric RNAs in our study led to different conclusions as well. The differences could be due to differences in the conditions under which the experiments were conducted such as ionic strength, temperature, pRNA concentration, the secondary structure models used to design mutants, and the use of shorter ( $75 \mathrm{nt})$ RNAs comprising just the multimerization domain. Based on our SHAPE probing for different pRNAs (Fig. 3), it was clear that the secondary structures of Chen et al. (1999) were largely correct and this is the model we used (Chen et al. 1999). Overall, the studies are complementary and their differences indicate the subtle behaviors of pRNAs and how readily the behaviors of these RNAs can be modulated. 
A
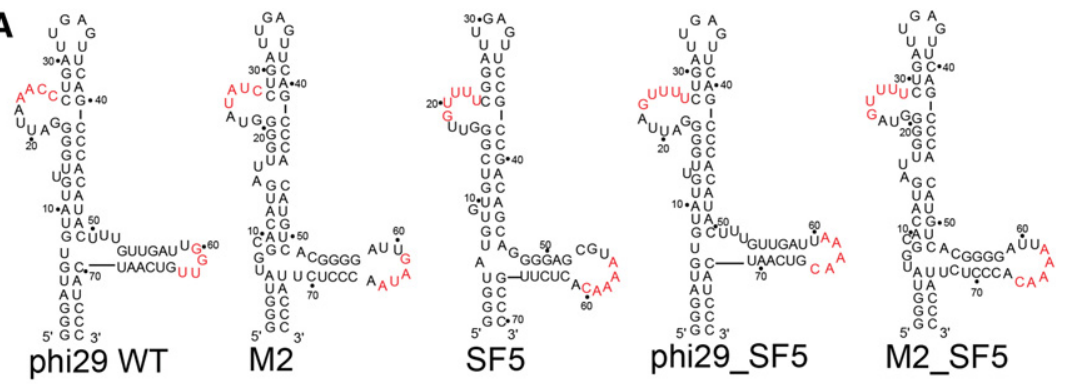

B

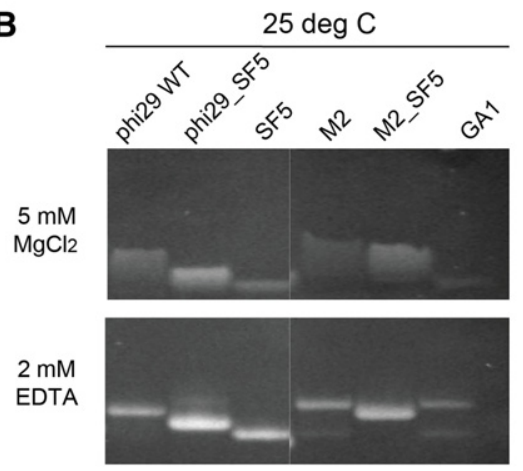

FIGURE 7. Native gel electrophoresis of chimeric mutants testing the M2 scaffold. (A) Secondary structures of the chimeric RNAs. Both chimeric RNAs have SF5's kissing hairpin with either phi29 scaffold (phi29_SF5) or M2 scaffold (M2_SF5). Wild-type phi29, M2, and SF5 RNAs are included for comparison. The predicted kissing sequences are shown in red. $(B)$ Native gel electrophoresis of the RNAs in panel A. Gels containing $5 \mathrm{mM} \mathrm{MgCl}_{2}$ are shown above while those with $2 \mathrm{mM}$ EDTA are shown below.

One novel aspect of our studies is a systematic examination of the ability of different pRNAs to multimerize at different temperatures. pRNA self-association has been extensively studied using native gel electrophoresis; however, most of the studies only examined multimerization at a single temperature $\left(4^{\circ} \mathrm{C}\right)$ (Guo et al. 1998; Chen et al. 2000; Gu and Schroeder 2011). Our native gel results at three different temperatures indicate that $\mathrm{pRNAs}$ from different strains have different abilities to maintain the multimeric state and different stoichiometries at higher temperature $\left(25^{\circ} \mathrm{C}\right.$ and $\left.37^{\circ} \mathrm{C}\right)$. For example, while M2 pRNA forms a trimer at lower temperature, it switches to primarily a dimer at $25^{\circ} \mathrm{C}$. This suggests that future applications of pRNA in engineering or therapeutics should carefully examine temperature effects, which could be exploited in a rational way. In addition, although sedimentation velocity analytical ultracentrifugation (SVAUC) has been applied to characterize pRNA multimerization (Gu and Schroeder 2011), our study is the first to use sedimentation equilibrium analytical ultracentrifugation (SE-AUC) to examine a diverse family of pRNAs. We demonstrate the suitability of this method for exploring self-associating RNA, particularly when coupled with other methods. Because the SE-AUC method provides stoichiometric information independent of molecular size and shape, it should be useful for more detailed thermodynamic examinations of diverse mutants under equilibrium conditions.
Our data support the conclusion that the differing abilities of various pRNAs to self-associate and the stability of the resultant multimers are determined by multiple factors. One feature that affects the ability is the number of base pairs the kissing interaction can form. For example, the GA1 pRNA we tested putatively has only two base pairs in the kissing interaction and we do not detect multimers at any temperature, while those with four or five potential pairs form multimers. However, the multimer stability does not directly track with the number of potential base pairs. SF5 might form five pairs in the kissing interaction but does not multimerize at $25^{\circ} \mathrm{C}$, while $\mathrm{M} 2$ and B103, which have the potential to form only four base pairs, multimerize at this temperature. This might be due to several effects: (1) differences in the ability of the base pairs to stack and thus form helical elements of different stabilities, (2) structures within the kissing hairpins that form additional noncanonical interactions, (3) the presence of competing structures, or (4) perhaps the number of base pairs formed in each kissing interaction differs from that predicted. Furthermore, the fact that these different pRNAs form multimers of different stoichiometry is not readily explained by differing kissing interactions, and the fact that the characteristics of one pRNA species are not readily transferred to another through the kissing interaction strongly suggests that other features are important for different pRNA behaviors. Our results show that in general the constructs built on the M2 pRNA scaffold and containing the M2 3wj more stably self-associate and form larger multimers than those built on the phi29 pRNA scaffold. Because the 3wj was the only other major structural element present in the RNAs we used and it differs substantially between pRNAs, we hypothesize that it plays a major role in determining the individual self-association characteristics of each pRNA.

RNA 3wjs often facilitate long-range contacts by arranging the emerging helices at specific angles (Lescoute and Westhof 2006), and in pRNAs the structure of the 3wj may facilitate self-association by placing the kissing loops in a geometry that favors formation of specific multimers (Zhang et al. 2012; Zhao et al. 2012). Although only the 3 wj specifically from the phi2 9 pRNA has been studied, those studies may lend insight into how the junctions of other pRNAs could modulate self-association. The crystal structure of a tetrameric form of phi29 pRNA showed helices $\mathrm{P}_{\mathrm{A}}$ and $\mathrm{P}_{\mathrm{C}}$ to be coaxially stacked with helix $\mathrm{P}_{\mathrm{C}}$ emerging at an angle of $\sim 70^{\circ}$ (Ding et al. 2011). The crystal structure of the isolated phi29 3 wj core 
showed similar helical arrangements, with some difference in the angle between $\mathrm{P}_{\mathrm{A}}$ and $\mathrm{P}_{\mathrm{C}}$ (Zhang et al. 2013). Interestingly, when the phi29 pRNA was studied using solution methods such as single-molecule FRET and electron paramagnetic resonance, the resultant models show a coaxial stacking of $\mathrm{P}_{\mathrm{C}}$ and $\mathrm{P}_{\mathrm{D}}$, with $\mathrm{P}_{\mathrm{A}}$ emerging at an angle, a conformation also suggested by computer modeling (Hoeprich and Guo 2002; Shu et al. 2010; Zhang et al. 2012). In addition, it has been shown that the UUU triplet at nucleotides $50-52$ in the phi29 pRNA 3wj is important for helical conformation and phage DNA packaging, leading to the proposal that inherent flexibility in the junction is important for function (Zhao et al. 2012). This feature would explain the different conformations observed in the biophysical and structural studies. These data suggest a mechanism for phi29 pRNA self-association in which the 3 wj dynamically samples a conformational landscape until intermolecular interactions stabilize one state in a form of "tertiary capture." The plasticity in arrangements of the helices would allow different oligomeric states depending on conditions and explain the published observations; e.g., in solution a dimer is thermodynamically favored, crystal contacts could drive tetramer formation, and interactions within the packaging motor favor even higher-order multimers.

The aforementioned features of the phi29 pRNA can now be used to develop a model for how the other pRNA 3wj's could induce different behaviors. Using the fact that 3 wjs have been cataloged into families based on topology, the classification rules place phi29 pRNA's 3 wj into family “A," a form in which conformational flexibility is a feature (Lescoute and Westhof 2006). In the crystal structure of the phi29 pRNA in tetrameric form (Ding et al. 2011), the junction does have some family A characteristics: $\mathrm{P}_{\mathrm{A}}$ and $\mathrm{P}_{\mathrm{C}}$ stack, and there are few tertiary contacts in the junction. However, $P_{D}$ emerges from the junction at $\sim 70^{\circ} \mathrm{C}$ angle, a defining characteristic of family "B." This analysis suggests that to multimerize, the state favored by the phi29 pRNA 3 wj in the monomeric form (family A) must be "captured" in a different state (family B); this is consistent with inherent flexibility in the junction. If we apply this analysis to the 3 wj from M2's pRNA, a different situation emerges. The 3 wj of M2 pRNA is predicted to be a member of family $B$, the conformation observed in the tetrameric crystal structure and thus likely favorable for self-association. Thus, the ability of M2 pRNA to form multimers of higher stoichiometry and stability than that of phi29 is likely due to the 3 wj favoring a specific conformation conducive to self-association. By extension, the diverse self-association behavior of pRNAs from different strains is likely dependent on subtle differences in the flexibility of each junction and the specific conformation landscape sampled by each.

More detailed analysis of 3wj's other than those found in pRNAs may lend additional tools and insight useful for the development of nanostructures through RNA engineering. The fact that different versions of the pRNA have different stabilities, indicated by diverse behaviors at different temperatures, is an interesting feature that impacts the use of pRNAs in nanotechnology engineering. Exploiting the pRNA's multimerization properties as a tool for gene therapy or for delivery of various other RNA cargos may require pRNAs with different multimerization stabilities. The pRNA from phi29 is the most studied and tested, but it may not be the best if multimerization at temperatures approaching $37^{\circ} \mathrm{C}$ are needed. Although a full exploration of different kissing interaction-scaffold combinations is beyond the scope of this study, our results suggest that the most stable multimers could be built on the M2 scaffold. In fact, it may be possible to engineer or select for other artificial scaffolds that are even more conducive to multimerization.

Finally, the question could be asked as to why we did not observe multimers above trimer by any pRNA in any of our experiments. Although there is some disagreement in the literature about whether five or six copies exist in the fully assembled ring (Garver and Guo 1997, 2000; Guo et al. 1998; Chen et al. 2000; Shu et al. 2007; Morais et al. 2008), it is clear that the pRNA forms higher-order complexes in its final biologically functional state. It is very likely that hexamers, pentamers, or tetramers are thermodynamically unstable when free in solution. Indeed, our observations of dimers and trimers are consistent with the aforementioned previous study (Gu and Schroeder 2011); stable production of a substantial population of larger-order complexes in solution may require very specific conditions not readily replicated. While we cannot exclude the possibility that the lack of larger multimers is due to the use of our minimal ( $\sim 75$-nt long) self-association constructs, it seems more likely that interactions with other components of the motor stabilize the larger ring structures. Indeed, it has been proposed for phi29 that smaller complexes are intermediates on the pathway to larger rings (Chen et al. 2000), and so a reasonable model is that the interaction of these intermediate-sized complexes with the other components of the motor leads to rearrangement into the larger ring structure.

\section{MATERIALS AND METHODS}

\section{RNA preparation}

RNAs for native gels, analytical ultracentrifugation and DMS probing were made using DNA generated by PCR using overlapping primers to make the DNA template (Kieft et al. 2007). RNAs were generated by in vitro transcription using the PCR products, and purified on $10 \%$ polyacrylamide (29:1 bisacrylamide:acrylamide) $7 \mathrm{M}$ urea denaturing gels. Bands were identified using UV shadowing and then excised and eluted in RNase-free water overnight at $4^{\circ} \mathrm{C}$. The eluted solution was then concentrated using Amicon Ultra filters (Millipore). pRNA concentrations were measured by UV absorbance at $260 \mathrm{~nm}$ (Nanodrop 2000c, Thermo Scientific).

\section{Nondenaturing gel electrophoresis}

Nondenaturing gel electrophoresis experiments were performed as described (Kieft et al. 2007). Three micrograms of RNA in a total 
volume of $10 \mu \mathrm{L}$ was loaded. The pRNA sample was renatured by heating to $85^{\circ} \mathrm{C}$ for $15 \mathrm{sec}$ in Mg-Buffer $(66 \mathrm{mM}$ Tris, $34 \mathrm{mM}$ HEPES, $5 \mathrm{mM} \mathrm{MgCl}_{2}$, pH 7.4) or EDTA-Buffer (66 mM Tris, 34 $\mathrm{mM}$ HEPES, 2 mM EDTA, pH 7.4) then snap cooled on ice. Samples were mixed with equal volume of $2 \times$ native gel loading buffer (132 mM Tris, $68 \mathrm{mM}$ HEPES, $10 \%$ glycerol, $0.5 \mathrm{mg} / \mathrm{mL}$ bromophenol blue, $0.5 \mathrm{mg} / \mathrm{mL}$ xylene cyanol, $\mathrm{pH} 7.4$ with either 10 $\mathrm{mM} \mathrm{MgCl}_{2}$ for $\mathrm{Mg}^{2+}$ gels or $4 \mathrm{mM}$ EDTA for EDTA gels) and were run on an $8 \%$ polyacrylamide native gel (29:1 bisacrylamide: acrylamide with $\mathrm{Mg}$-buffer for $\mathrm{Mg}^{2+}$ gels or EDTA-buffer for EDTA gels). Both gel and buffer were preincubated at desired temperatures and the gels were prerun for $20 \mathrm{~min}$ at $5 \mathrm{~W}$. Gels were run at $5 \mathrm{~W}$ for $10 \mathrm{~h}$ and then stained with $1 \%$ ethidium bromide for visualization.

\section{Sedimentation velocity analytical ultracentrifugation}

RNA samples for SV-AUC experiments were diluted to obtain an absorbance at $260 \mathrm{~nm}$ of $\sim 0.7$, then dialyzed into AUC buffer (10 $\mathrm{mM}$ sodium cacodylic acid, $5 \mathrm{mM} \mathrm{MgCl}_{2}, \mathrm{pH} 7.5$ ). Experiments were carried out at $12^{\circ} \mathrm{C}$ and $25^{\circ} \mathrm{C}$ in an Optima XL-I Analytical Ultracentrifuge (Beckman) using cells with two-sector centerpieces and quartz windows in an An-60Ti 4-Place Analytical Rotor (Beckman). Samples were initially spun at $3000 \mathrm{rpm}$ and the absorbance recorded to verify sample loading concentration and no leakage, then spun at $40,000 \mathrm{rpm}$ for $12 \mathrm{~h}$ to record scans. Absorbance profiles were recorded at $260 \mathrm{~nm}$ at regular intervals. The sedimentation process was considered complete when 10 consecutive scans did not show a change as a function of time. Results were analyzed with Svedberg (Philo 1997; Schuck and Demeler 1999).

\section{Sedimentation equilibrium analytical ultracentrifugation}

SE-AUC was performed in a Beckman-Coulter XL-A centrifuge using UV absorption optics, cells with six-sector centerpieces and quartz windows, and an An-60Ti 4-Place Analytical Rotor (Beckman). Samples are prepared at three different initial loading concentrations from 1 to $10 \mu \mathrm{M}$ in AUC buffer $(10 \mathrm{mM}$ sodium cacodylic acid, $5 \mathrm{mM} \mathrm{MgCl}_{2}, \mathrm{pH}$ 7.5). Experiments were performed at two temperatures, $4^{\circ} \mathrm{C}$ and $25^{\circ} \mathrm{C}$, and three different speeds $(10,12$, and $20 \mathrm{~K} \mathrm{rpm}$ at $4^{\circ} \mathrm{C} ; 12,15$, and $24 \mathrm{~K} \mathrm{rpm}$ at $25^{\circ} \mathrm{C}$ ). Samples were centrifuged at each speed for $12 \mathrm{~h}$ and absorbance scans were obtained every $3 \mathrm{~h}$ at $270 \mathrm{~nm}$. Equilibrium was achieved when no change in these concentration profiles as a function of time was observed. Data were analyzed by Heteroanalysis software version 1.1.58 (Analytical Ultracentrifugation facility, Biotechnology Bioservices Center, University of Connecticut). Data at each rotor speed were fitted globally to a single molecular species model:

$$
S(r, \lambda)=\delta_{\lambda}+\varepsilon_{\lambda} C_{0} \exp \left[M(1-\bar{v} \rho) \frac{\omega^{2}}{2 R T}\left(r^{2}-r_{0}^{2}\right)\right],
$$

where $S(r, \lambda)$ is the radially-dependent signal at wavelength $\lambda, \delta_{\lambda}$ is the baseline offset at wavelength $\lambda$, $\varepsilon_{\lambda}$ is the molar extinction coefficient at wavelength $\lambda, C_{0}$ is the molar concentration of the monomer at the arbitrary reference distance $r_{0}$, and $M$ is the molecular weight of the monomer. Values for $\rho$, the solvent density of AUC buffer and $\bar{v}$, the partial specific volume, were obtained from previously published work (Wood et al. 2005); $\rho=0.998 \mathrm{~g} / \mathrm{cm}^{3}, \bar{v}=0.455 \mathrm{~mL} \mathrm{~g}^{-1}$ was used in this study. $\omega$ is the angular velocity of the rotor in radians/ sec, $R$ is the molar gas constant $(83,144,000 \mathrm{erg} / \mathrm{mol} / \mathrm{K})$, and $T$ is the absolute temperature. Data were also fitted to a reversible self-association monomer-Nmer model to analyze samples that could form mixtures of monomer, dimer, and trimer species:

$$
\begin{aligned}
S(r, \lambda) & =\delta_{\lambda}+\varepsilon_{\lambda} C_{0} \exp \left[M(1-\bar{\nu} \rho) \frac{\omega^{2}}{2 R T}\left(r^{2}-r_{0}^{2}\right)\right] \\
& +N \varepsilon_{\lambda} C_{0}^{N} \exp \left[\ln K+N M(1-\bar{\nu} \rho) \frac{\omega^{2}}{2 R T}\left(r^{2}-r_{0}^{2}\right)\right],
\end{aligned}
$$

where $N$ is the stoichiometry of the association reaction and $\ln K$ is the natural logarithm of the association constant, $K$.

\section{Radiolabeling primers for probing}

RNA primers were $5^{\prime}$-radiolabeled in a reaction containing $40 \mu \mathrm{M}$ of purified primer, $2 \mu \mathrm{L}$ of $10 \times$ polynucleotide kinase (PNK) buffer $(70$ $\mathrm{mM}$ Tris- $\mathrm{HCl}$ at $\mathrm{pH} 7.6,10 \mathrm{mM} \mathrm{MgCl}_{2}, 5 \mathrm{mM}$ DTT, New England Biolabs), $2 \mu \mathrm{L}$ of T4 PNK (10,000 U/mL, New England Biolabs), 1 $\mu \mathrm{L}$ of $\gamma^{-32} \mathrm{P}$-ATP (PerkinElmer, $6000 \mathrm{Ci} / \mathrm{mmol}$ ) in a final volume of $20 \mu \mathrm{L}$. Reactions were incubated at $35^{\circ} \mathrm{C}$ for $1 \mathrm{~h}$ and then added to $10 \mu \mathrm{L} 9 \mathrm{M}$ urea loading buffer and loaded on a $10 \%$ polyacrylamide (29:1 bisacrylamide:acrylamide) $7 \mathrm{M}$ urea denaturing gel $(16.5 \mathrm{~cm} \times 3.25 \mathrm{~cm} \times 3.1 \mathrm{~mm})$ and electrophoresed at $25 \mathrm{~W}$ for $15 \mathrm{~min}$. Gels were visualized by autoradiography, then the primer bands were excised and eluted passively in elution buffer $(0.5 \mathrm{M}$ sodium acetate, $0.1 \%$ SDS, pH 5.3) overnight. This was followed by ethanol precipitation and the dried pellet was resuspended in RNase-free water prior to use.

\section{SHAPE analysis}

Six picomoles of RNA in $8 \mu \mathrm{L}$ of RNase-free water was heated to $85^{\circ}$ $\mathrm{C}$ for $30 \mathrm{sec}$, then cooled on the desktop. Two microliters of RNA folding buffer (333 mM HEPES $\mathrm{pH} 8.0,20 \mathrm{mM} \mathrm{MgCl}_{2}, 333 \mathrm{mM}$ $\mathrm{NaCl}$ ) was added. One microliter of DMSO was added to the DMSO controls and $1 \mu \mathrm{L}$ of 50,100 , or $150 \mathrm{mM} \mathrm{N}$-methylisatoic anhydride (NMIA) prepared in DMSO was added to the experimental reactions. Reactions were incubated at $37^{\circ} \mathrm{C}$ for $1 \mathrm{~h}$ and then desalted using Micro Bio-Spin 30 Tris Chromatography Columns (BioRad). Reverse transcription (RT) was done with $1 \mu \mathrm{L}$ of one of the following primers: M2 primer (5'-GGGTAAGTGGGTTATCAAT$\left.3^{\prime}\right)$, SF5 primer (5'-GGGCAAGAGTGTTTTACGCTC-3'), GA1 primer (5'-GGTAGTATTGCTACCTCGCAAC-3'), or B103 primer (5'-GGGTAAGTGGGCTATCAATCC-3'), which were $5^{\prime}$-end labeled with ${ }^{32} \mathrm{P}$ and diluted to $30,000 \mathrm{cpm} / \mu \mathrm{L}$. Reverse transcription was performed as described (Kieft et al. 2007; Filbin and Kieft 2011). Gels were aligned using the Semi-Automated Footprinting Analysis (SAFA) software (Das et al. 2005) and different lanes were normalized to total radiation using ImageQuant software followed by background subtraction of the control lanes in Microsoft Excel.

\section{Dimethyl sulfate probing}

Ten picomoles of RNA in $8 \mu \mathrm{L}$ of RNase-free water with $2 \mu \mathrm{L}$ of $5 \times$ DMS probing buffer (400 mM sodium cacodylic acid $\mathrm{pH} 7.2,500$ $\mathrm{mM} \mathrm{KCl}$ and $25 \mathrm{mM} \mathrm{MgCl} 2$ for $\mathrm{Mg}^{2+}$ probing or $10 \mathrm{mM}$ EDTA 
for EDTA probing) was heated to $85^{\circ} \mathrm{C}$ for $30 \mathrm{sec}$, then cooled on the bench. Two microliters of $95 \%$ ethanol was added to the controls and $2 \mu \mathrm{L}$ of $2.64 \mathrm{M}$ DMS (Sigma) in 95\% ethanol was added to the reactions. Reactions were incubated at desired temperature for $10 \mathrm{~min}$ and then quenched with $5 \mu \mathrm{L}$ DMS stop buffer (1.0 M Tris- $\mathrm{HCl}$ pH 7.5, 0.1 M EDTA, and $1 \mathrm{M} \beta$-mercaptoethanol). Micro BioSpin 30 Tris Chromatography Columns (Bio-Rad) were used to clean up the reactions. Reverse transcription (RT) was done with 1 $\mu \mathrm{L}$ of one of the following primers: phi29 wt (5'-GGGATGATT GACAACCAATCAAC-3'), COM and MUT1 primer (5'-GGGATG ATTGACCCGTAATC-3'), MUT2 primer (5'-GGGATGATTGAC AACCAATC-3'), M2 primer (5'-GGGTAAGTGGGTTATCAAT- $3^{\prime}$ ), SF5 primer ( $5^{\prime}$-GGGCAAGAGTGTTTTACGCTC-3'), GA1 primer (5'-GGTAGTATTGCTACCTCGCAAC-3'), B103 primer (5'-GGG TAAGTGGGCTATCAATCC-3'), SF5_phi29 primer (5'-GGGCAA GAGAACCACTCCCC-3'), or SF5_M2 primer (5'-GGGCAAGA GTTATCAATCTC- $3^{\prime}$ ), which were $5^{\prime}$-end labeled with ${ }^{32} \mathrm{P}$ and diluted to $30,000 \mathrm{cpm} / \mu \mathrm{L}$. Reverse transcription reactions and sequencing gels were run as described (Tijerina et al. 2007; Filbin and Kieft 2011). Gels were aligned using the Semi-Automated Footprinting Analysis (SAFA) software and different lanes were normalized to total radiation using ImageQuant software followed by background subtraction of the control lanes in Microsoft Excel.

\section{ACKNOWLEDGMENTS}

The authors thank Dr. Robert T. Batey and Dr. Chad G. Pearson for critical reading of the manuscript and insightful comments, and current and former Kieft Lab members for thoughtful discussions and technical assistance. We also thank Jeffrey W. Lary at University of Connecticut for Heteroanalysis program assistance and Rolando Deangelis at University of Colorado for SE-AUC discussions. J.S.K. is an Early Career Scientist of the Howard Hughes Medical Institute. Y.H. is an American Heart Association Predoctoral Fellow (13PRE14500042).

Received April 18, 2014; accepted August 18, 2014.

\section{REFERENCES}

Aathavan K, Politzer AT, Kaplan A, Moffitt JR, Chemla YR, Grimes S, Jardine PJ, Anderson DL, Bustamante C. 2009. Substrate interactions and promiscuity in a viral DNA packaging motor. Nature 461: 669-673.

Bailey S, Wichitwechkarn J, Johnson D, Reilly BE, Anderson DL, Bodley JW. 1990. Phylogenetic analysis and secondary structure of the Bacillus subtilis bacteriophage RNA required for DNA packaging. J Biol Chem 265: 22365-22370.

Bourassa N, Major F. 2002. Implication of the prohead RNA in phage phi29 DNA packaging. Biochimie 84: 945-951.

Chen C, Guo P. 1997a. Magnesium-induced conformational change of packaging RNA for procapsid recognition and binding during phage phi29 DNA encapsidation. J Virol 71: 495-500.

Chen C, Guo P. 1997b. Sequential action of six virus-encoded DNApackaging RNAs during phage phi29 genomic DNA translocation. J Virol 71: 3864-3871.

Chen C, Zhang C, Guo P. 1999. Sequence requirement for hand-inhand interaction in formation of RNA dimers and hexamers to gear phi29 DNA translocation motor. RNA 5: 805-818.

Chen C, Sheng S, Shao Z, Guo P. 2000. A dimer as a building block in assembling RNA. A hexamer that gears bacterial virus phi29 DNAtranslocating machinery. J Biol Chem 275: 17510-17516.
Das R, Laederach A, Pearlman SM, Herschlag D, Altman RB. 2005. SAFA: semi-automated footprinting analysis software for highthroughput quantification of nucleic acid footprinting experiments. RNA 11: 344-354.

Dibrov SM, McLean J, Parsons J, Hermann T. 2011. Self-assembling RNA square. Proc Natl Acad Sci 108: 6405-6408.

Ding F, Lu C, Zhao W, Rajashankar KR, Anderson DL, Jardine PJ, Grimes S, Ke A. 2011. Structure and assembly of the essential RNA ring component of a viral DNA packaging motor. Proc Natl Acad Sci 108: 7357-7362.

Fang Y, Shu D, Xiao F, Guo P, Qin PZ. 2008. Modular assembly of chimeric phi29 packaging RNAs that support DNA packaging. Biochem Biophys Res Commun 372: 589-594.

Filbin ME, Kieft JS. 2011. HCV IRES domain IIb affects the configuration of coding RNA in the 40 S subunit's decoding groove. RNA 17: $1258-1273$.

Fu CY, Uetrecht C, Kang S, Morais MC, Heck AJ, Walter MR, Prevelige PE Jr. 2010. A docking model based on mass spectrometric and biochemical data describes phage packaging motor incorporation. Mol Cell Proteomics 9: 1764-1773.

Fuller DN, Rickgauer JP, Jardine PJ, Grimes S, Anderson DL, Smith DE. 2007. Ionic effects on viral DNA packaging and portal motor function in bacteriophage phi 29. Proc Natl Acad Sci 104: 11245-11250.

Garver K, Guo P. 1997. Boundary of pRNA functional domains and minimum pRNA sequence requirement for specific connector binding and DNA packaging of phage phi29. RNA 3: 1068-1079.

Garver K, Guo P. 2000. Mapping the inter-RNA interaction of bacterial virus phi29 packaging RNA by site-specific photoaffinity cross-linking. J Biol Chem 275: 2817-2824.

Gu X, Schroeder SJ. 2011. Different sequences show similar quaternary interaction stabilities in prohead viral RNA self-assembly. J Biol Chem 286: 14419-14426.

Guasch A, Pous J, Ibarra B, Gomis-Ruth FX, Valpuesta JM, Sousa N, Carrascosa JL, Coll M. 2002. Detailed architecture of a DNA translocating machine: the high-resolution structure of the bacteriophage phi29 connector particle. J Mol Biol 315: 663-676.

Guo P. 2005. Bacterial virus phi29 DNA-packaging motor and its potential applications in gene therapy and nanotechnology. Methods Mol Biol 300: 285-324.

Guo PX, Bailey S, Bodley JW, Anderson D. 1987a. Characterization of the small RNA of the bacteriophage phi 29 DNA packaging machine. Nucleic Acids Res 15: 7081-7090.

Guo PX, Erickson S, Anderson D. 1987b. A small viral RNA is required for in vitro packaging of bacteriophage phi 29 DNA. Science 236: 690-694.

Guo P, Zhang C, Chen C, Garver K, Trottier M. 1998. Inter-RNA interaction of phage phi29 pRNA to form a hexameric complex for viral DNA transportation. Mol Cell 2: 149-155.

Guo S, Tschammer N, Mohammed S, Guo P. 2005. Specific delivery of therapeutic RNAs to cancer cells via the dimerization mechanism of phi29 motor pRNA. Hum Gene Ther 16: 1097-1109.

Guo S, Huang F, Guo P. 2006. Construction of folate-conjugated pRNA of bacteriophage phi29 DNA packaging motor for delivery of chimeric siRNA to nasopharyngeal carcinoma cells. Gene Ther 13: 814820.

Hoeprich S, Guo P. 2002. Computer modeling of three-dimensional structure of DNA-packaging RNA (pRNA) monomer, dimer, and hexamer of Phi29 DNA packaging motor. J Biol Chem 277: 2079420803.

Hugel T, Michaelis J, Hetherington CL, Jardine PJ, Grimes S, Walter JM, Falk W, Anderson DL, Bustamante C. 2007. Experimental test of connector rotation during DNA packaging into bacteriophage phi29 capsids. PLoS Biol 5: e59.

Ishikawa J, Furuta H, Ikawa Y. 2013. RNA tectonics (tectoRNA) for RNA nanostructure design and its application in synthetic biology. Wiley Interdiscip Rev RNA 4: 651-664.

Khisamutdinov EF, Jasinski DL, Guo P. 2014. RNA as a boiling-resistant anionic polymer material to build robust structures with defined shape and stoichiometry. ACS Nano 8: 4771-4781. 
Kieft JS, Costantino DA, Filbin ME, Hammond J, Pfingsten JS. 2007. Structural methods for studying IRES function. Methods Enzymol 430: 333-371.

Ko SH, Su M, Zhang C, Ribbe AE, Jiang W, Mao C. 2010. Synergistic self-assembly of RNA and DNA molecules. Nat Chem 2: 1050-1055.

Lee TJ, Schwartz C, Guo P. 2009. Construction of bacteriophage phi29 DNA packaging motor and its applications in nanotechnology and therapy. Ann Biomed Eng 37: 2064-2081.

Lee JB, Hong J, Bonner DK, Poon Z, Hammond PT. 2012. Self-assembled RNA interference microsponges for efficient siRNA delivery. Nat Mater 11: 316-322.

Lescoute A, Westhof E. 2006. Topology of three-way junctions in folded RNAs. RNA 12: 83-93.

Li L, Liu J, Diao Z, Shu D, Guo P, Shen G. 2009. Evaluation of specific delivery of chimeric phi29 pRNA/siRNA nanoparticles to multiple tumor cells. Mol Biosyst 5: 1361-1368.

Meijer WJ, Horcajadas JA, Salas M. 2001. Phi29 family of phages. Microbiol Mol Biol Rev 65: 261-287.

Morais MC, Koti JS, Bowman VD, Reyes-Aldrete E, Anderson DL, Rossmann MG. 2008. Defining molecular and domain boundaries in the bacteriophage phi29 DNA packaging motor. Structure 16: $1267-1274$.

Pecenkova T, Paces V. 1999. Molecular phylogeny of phi29-like phages and their evolutionary relatedness to other protein-primed replicating phages and other phages hosted by Gram-positive bacteria. J Mol Evol 48: 197-208.

Philo JS. 1997. An improved function for fitting sedimentation velocity data for low-molecular-weight solutes. Biophys J 72: 435-444.

Rao VB, Feiss M. 2008. The bacteriophage DNA packaging motor. Annu Rev Genet 42: 647-681.

Reid RJ, Bodley JW, Anderson D. 1994a. Characterization of the prohead-pRNA interaction of bacteriophage phi 29. J Biol Chem 269: 5157-5162.

Reid RJ, Bodley JW, Anderson D. 1994b. Identification of bacteriophage phi 29 prohead RNA domains necessary for in vitro DNA-gp3 packaging. J Biol Chem 269: 9084-9089.

Robinson MA, Wood JP, Capaldi SA, Baron AJ, Gell C, Smith DA, Stonehouse NJ. 2006. Affinity of molecular interactions in the bacteriophage phi29 DNA packaging motor. Nucleic Acids Res 34: 2698-2709.

Schuck P, Demeler B. 1999. Direct sedimentation analysis of interference optical data in analytical ultracentrifugation. Biophys $J$ 76: 2288-2296.

Serwer P. 2003. Models of bacteriophage DNA packaging motors. $J$ Struct Biol 141: 179-188.

Shu D, Zhang H, Jin J, Guo P. 2007. Counting of six pRNAs of phi29 DNA-packaging motor with customized single-molecule dual-view system. EMBO J 26: 527-537.

Shu D, Zhang H, Petrenko R, Meller J, Guo P. 2010. Dual-channel single-molecule fluorescence resonance energy transfer to establish distance parameters for RNA nanoparticles. ACS Nano 4: 68436853.
Shu D, Shu Y, Haque F, Abdelmawla S, Guo P. 2011. Thermodynamically stable RNA three-way junction for constructing multifunctional nanoparticles for delivery of therapeutics. Nat Nanotechnol 6: 658-667.

Simpson AA, Leiman PG, Tao Y, He Y, Badasso MO, Jardine PJ, Anderson DL, Rossmann MG. 2001. Structure determination of the head-tail connector of bacteriophage phi29. Acta Crystallogr D Biol Crystallogr 57: 1260-1269.

Smith DE, Tans SJ, Smith SB, Grimes S, Anderson DL, Bustamante C. 2001. The bacteriophage straight phi29 portal motor can package DNA against a large internal force. Nature 413: 748-752.

Tarapore P, Shu Y, Guo P, Ho SM. 2011. Application of phi29 motor pRNA for targeted therapeutic delivery of siRNA silencing metallothionein-IIA and survivin in ovarian cancers. Mol Ther 19: 386-394.

Tijerina P, Mohr S, Russell R. 2007. DMS footprinting of structured RNAs and RNA-protein complexes. Nat Protoc 2: 2608-2623.

Trottier M, Mat-Arip Y, Zhang C, Chen C, Sheng S, Shao Z, Guo P. 2000. Probing the structure of monomers and dimers of the bacterial virus phi29 hexamer RNA complex by chemical modification. RNA 6: $1257-1266$.

Wendell D, Jing P, Geng J, Subramaniam V, Lee TJ, Montemagno C, Guo P. 2009. Translocation of double-stranded DNA through membrane-adapted phi29 motor protein nanopores. Nat Nanotechnol 4: $765-772$.

Westhof E, Masquida B, Jaeger L. 1996. RNA tectonics: towards RNA design. Fold Des 1: R78-R88.

Wilkinson KA, Merino EJ, Weeks KM. 2006. Selective 2'-hydroxyl acylation analyzed by primer extension (SHAPE): quantitative RNA structure analysis at single nucleotide resolution. Nat Protoc 1: $1610-1616$.

Wood JPA, Capaldi SA, Robinson MA, Baron AJ, Stonehouse NJ. 2005. RNA multimerisation in the DNA packaging motor of bacteriophage Q29. J Theor Med 6: 127-134.

Yan H. 2004. Materials science. Nucleic acid nanotechnology. Science 306: 2048-2049.

Ye X, Hemida M, Zhang HM, Hanson P, Ye Q, Yang D. 2012. Current advances in Phi29 pRNA biology and its application in drug delivery. Wiley Interdiscip Rev RNA 3: 469-481.

Zhang C, Tellinghuisen T, Guo P. 1997. Use of circular permutation to assess six bulges and four loops of DNA-packaging pRNA of bacteriophage phi29. RNA 3: 315-323.

Zhang X, Tung CS, Sowa GZ, Hatmal MM, Haworth IS, Qin PZ. 2012. Global structure of a three-way junction in a phi29 packaging RNA dimer determined using site-directed spin labeling. J Am Chem Soc 134: 2644-2652.

Zhang H, Endrizzi JA, Shu Y, Haque F, Sauter C, Shlyakhtenko LS, Lyubchenko Y, Guo P, Chi YI. 2013. Crystal structure of 3WJ core revealing divalent ion-promoted thermostability and assembly of the Phi29 hexameric motor pRNA. RNA 19: 1226-1237.

Zhao W, Saha M, Ke A, Morais MC, Jardine PJ, Grimes S. 2012. A threehelix junction is the interface between two functional domains of prohead RNA in 29 DNA packaging. J Virol 86: 11625-11632. 

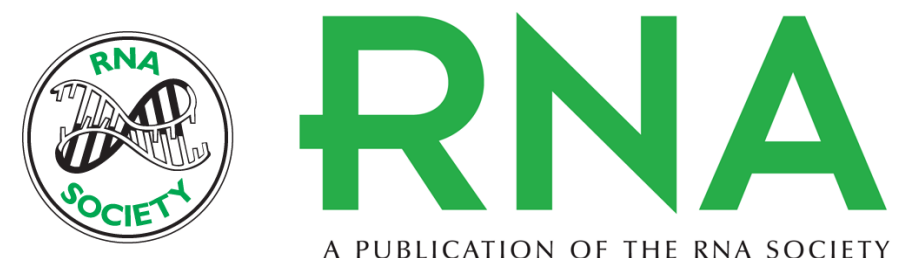

A PUBLICATION OF THE RNA SOCIETY

\title{
Diverse self-association properties within a family of phage packaging RNAS
}

\author{
Yumeng Hao and Jeffrey S. Kieft
}

RNA 2014 20: 1759-1774 originally published online September 22, 2014

Access the most recent version at doi:10.1261/rna.045948.114

\begin{abstract}
References This article cites 62 articles, 26 of which can be accessed free at: http://rnajournal.cshlp.org/content/20/11/1759.full.html\#ref-list-1

Creative This article is distributed exclusively by the RNA Society for the first 12 months after the Commons full-issue publication date (see http://rnajournal.cshlp.org/site/misc/terms.xhtml). After 12 License months, it is available under a Creative Commons License (Attribution-NonCommercial 4.0 International), as described at http://creativecommons.org/licenses/by-nc/4.0/.
\end{abstract}
Email Alerting Receive free email alerts when new articles cite this article - sign up in the box at the Service top right corner of the article or click here.

\section{|||||||| Providing Precise Solutions for your research.}

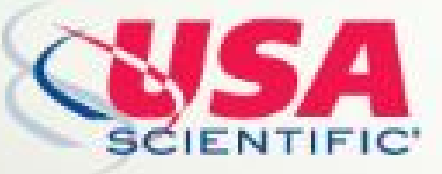

To subscribe to $R N A$ go to:

http://rnajournal.cshlp.org/subscriptions 